\title{
Time stretching: Illusory lengthening of filled auditory durations
}

\author{
TAKaYUKI Sasaki \\ Miyagi Gakuin Women's University, Sendai, Japan \\ Yoshitaka NAKaJIMA \\ Kyushu University, Fukuoka, Japan \\ Gert ten Hoopen, Edwin van BuUringen, ANd Bob Massier \\ Leiden University, Leiden, The Netherlands \\ AND \\ Taku Kojo, Tsuyoshi Kuroda, and Kazuo Ueda \\ Kyushu University, Fukuoka, Japan
}

\begin{abstract}
The second of two consecutively presented sounds may be perceived as being longer than if that sound had been presented in isolation. We performed five experiments using heterophonic patterns in which a sine tone was preceded by a frequency-band noise. We observed significant overestimations of sine-tone duration, the size of which depended on intensity and frequency differences between the band noise and the sine tone (Experiments 1 and 2). Band noises that were considerably shorter than the sine tone still caused significant overestimations (Experiment 3). A short silent gap between the band noise and the sine tone strongly reduced the amount of overestimation (Experiment 4). Both frozen and nonfrozen band noises yielded overestimations (Experiment 5). Our explanation for the overestimation is that the onset of the sine tone is blurred by the band noise and that such a blurred onset is restored at the level of perceptual organization following rules of a simple auditory grammar. This restoration takes mental processing time, which adds to the perceived duration of the sine tone. We call this illusion time stretching and discuss the notion that subsequent temporal assimilation and/or contrast effects can dilate or compress the amount of stretching.
\end{abstract}

In the last four decades, the discovery and interpretation of many illusions and anomalous phenomena in the auditory modality have given impetus to the study of auditory perception and cognition. Important contributions have been made by, among others, Bregman (1990), Deutsch (1986, 1999), Handel (1989), van Noorden (1975), and Warren $(1982,1999,2008)$. Many auditory phenomena that they describe pertain to processes in which time, pitch, and space interact (e.g., auditory streaming, scale illusion, and continuity illusion).

In a series of studies, we have reported an auditory illusion on the temporal dimension. This illusion, which we call time shrinking, is described as follows: When an empty time interval $t_{2}$ is immediately preceded by a shorter empty interval $t_{1}$, the duration of $t_{2}$ can be considerably underestimated (see Figure 1A for the temporal pattern). We give just two quantitative examples: (1) In the pattern $|50| 100 \mid$ msec (the symbol | represents a very short delimiting sound marker), the point of subjective equality (PSE) of $t_{2}$ is about $60 \mathrm{msec}$ (Nakajima, ten Hoopen, Hilkhuysen, \& Sasaki, 1992), and (2) in the pattern $|160| 240 \mid$ msec, the
PSE of $t_{2}$ is about $200 \mathrm{msec}$ (Nakajima, ten Hoopen, \& van der Wilk, 1991).

Time shrinking is very robust and stable (e.g., Suetomi \& Nakajima, 1998). The illusion can also be observed with sequences containing more than two time intervals (Remijn et al., 1999; Sasaki, Suetomi, Nakajima, \& ten Hoopen, 2002; ten Hoopen et al., 1995) and hardly disappears even when the sound markers delimiting the time intervals differ hugely in intensity (ten Hoopen et al., 1993) or in frequency (Remijn et al., 1999). The time-shrinking process seems, therefore, to operate within our central auditory system, rather than peripherally. For our explanation of the timeshrinking process, we refer to Nakajima, ten Hoopen, et al. (2004). That study also investigated the boundaries of the illusion, revealing that when the difference between $t_{2}$ and $t_{1}$ reaches about $100 \mathrm{msec}$, there is a sudden release from time shrinking, and when $t_{1}$ gets longer than about 200$240 \mathrm{msec}$, the illusion disappears as well. (See also Mitsudo et al., 2009, and Takeichi et al., in press, for electrophysiological evidence for temporal assimilation, including time shrinking.) 
A

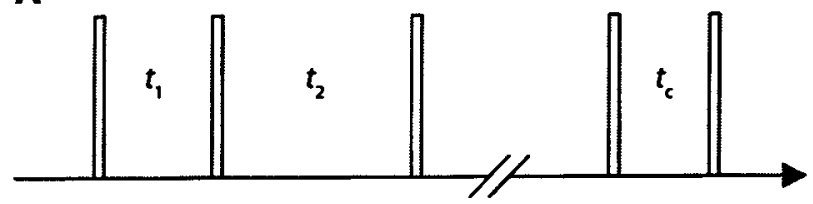

B

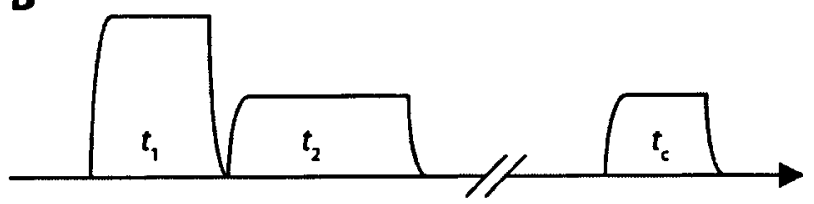

Figure 1. (A) Stimulus pattern in which the participant has to adjust a variable empty time interval $t_{c}$ (the comparison) to the empty time interval $t_{2}$ (the standard), which is preceded by a shorter empty time interval $t_{1}$. The bars represent very short sound markers delimiting the intervals. (B) Stimulus pattern in which the participant has to adjust a variable filled duration $t_{c}$ to the filled duration $t_{2}$ (the standard), which is preceded by a shorter filled duration $t_{1}$. The different heights of the filled durations represent the intensity-level difference necessary to distinguish $t_{2}$ from $t_{1}$.

If this illusion indeed arises at a central auditory level, it is reasonable to suppose that it can be observed with filled duration patterns as well. Sasaki, Nakajima, and ten Hoopen (1993) tested this hypothesis. Temporal patterns, comprising two $1-\mathrm{kHz}$ sine tones, were presented. In order to enable the listener to distinguish between the two contiguous filled durations $t_{1}$ and $t_{2}, t_{1}$ was presented at $76 \mathrm{~dB}$ SPL and $t_{2}$ at $70 \mathrm{~dB}$ SPL (see Figure 1B). In the same vein as our previous experiments (using empty intervals), $t_{2}$ had to be subjectively matched in duration by a variable comparison duration to establish the PSE of $t_{2}$. The values varied in 40-msec steps between 40 and $280 \mathrm{msec}$ for $t_{1}$ and between 80 and $280 \mathrm{msec}$ for $t_{2}$. On the assumption that time shrinking operates similarly on both filled and empty duration patterns, the expectation was that $t_{2}$ could be underestimated in $\left|t_{1}\right| t_{2} \mid$ patterns in which $t_{2}-t_{1}$ is 40 or $80 \mathrm{msec}$. However, this was not the case: In almost all conditions, overestimation of the $t_{2}$ duration was found.

Because Sasaki et al. (1993) was reported in Japanese and may not be easily accessible, we reproduce Figure 2 from that study here, also as Figure 2. As can be seen, overestimation increased rapidly when the duration of the more intense leading tone increased from 80 to 120 to $160 \mathrm{msec}$, beyond which value the overestimation stayed approximately at plateau. The overestimation also increased approximately with increasing $t_{2}$ duration. The greatest overestimation of $t_{2}$ was $29 \mathrm{msec}$ (in the pattern 280-240 msec). The authors proposed that the perceptual process yielding this unexpected result might be related to the same process as that underlying the auditorycontinuity illusion.

Many investigators reported the illusory continuation of a sound if it was partly interrupted by another, more intense sound (e.g., Elfner \& Caskey, 1965; Houtgast, 1972; Plomp, 1981; Thurlow, 1957; Vicario, 1960; Warren, Obusek, \& Ackroff, 1972). In several studies, both sounds (the less and more intense ones) were alternated repeatedly, and the illusion has been aptly compared with the visual "picket fence effect" (Miller \& Licklider,

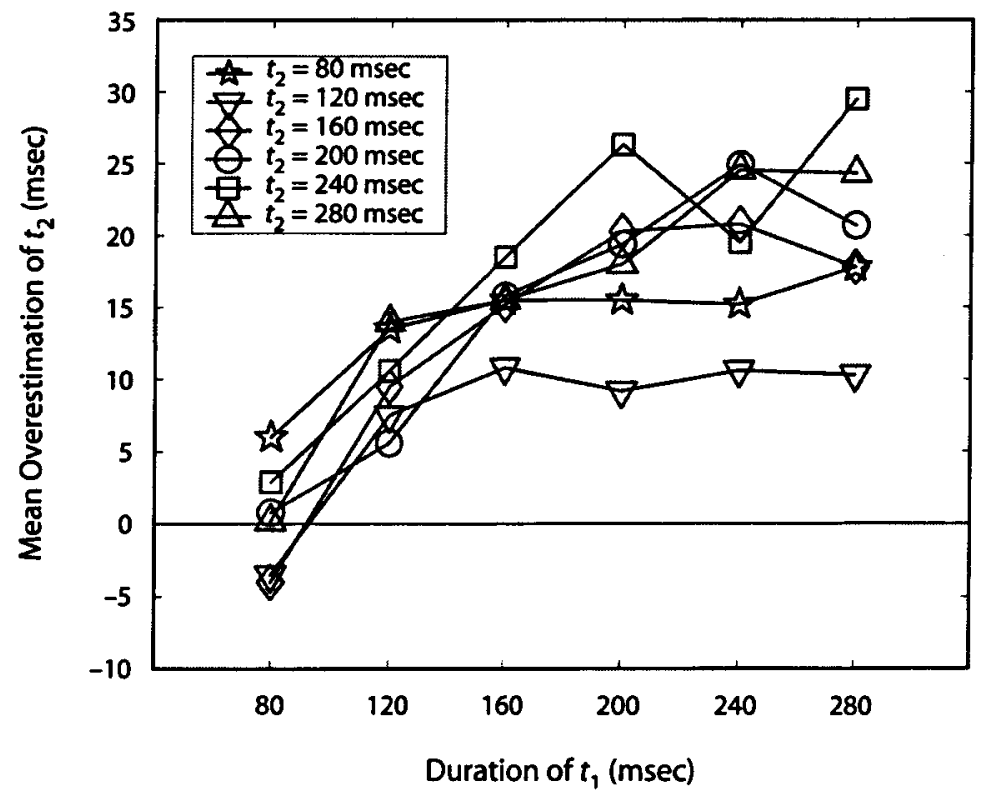

Figure 2. The overestimations of the second tone $\left(t_{2}\right)$ as a function of the durations of the first and second tones ( $t_{1}$ and $t_{2}$, respectively), as reported by Sasaki, Nakajima, and ten Hoopen (1993). From "The Effect of a Preceding Neighboring Tone on the Perception of Filled Durations," by T. Sasaki, Y. Nakajima, and G. ten Hoopen, 1993, Proceedings of the Acoustical Society of Japan, Spring Meeting, pp. 347-348. Copyright 1993 by the Acoustical Society of Japan. Adapted with permission. 
1950): The softer sound appears to continue behind the louder one. Vicario coined the term acoustic tunnel effect. The often-accepted explanation of the continuity illusion is the rule given by Warren et al. (1972): "If there is contextual evidence that a sound may be present at a given time, and if the peripheral units stimulated by a louder sound include those which would be stimulated by the anticipated fainter sound, then the fainter sound may be heard as present" (p. 1151). Although the classic studies that investigated the illusion of auditory continuity often used a paradigm of repeatedly cycling fainter and louder sounds (for an overview, see Plomp, 2002), it is clear that the smallest building block of the auditory picket fence is the sequence faint sound-loud sound-faint sound. There are indeed several examples indicating that the continuity illusion already works convincingly in such conditions (e.g., Bennett, Parasuraman, Howard, \& O'Toole, 1984; Ciocca \& Bregman, 1987; Kluender \& Jenison, 1992; Riecke, van Opstal, \& Formisano, 2008).

Ueda and Ohtsuki (1996) offered evidence against Sasaki et al.'s (1993) surmise that their finding might be related to the continuity illusion. They replicated Sasaki et al.'s study with an improvement: They varied the intensity-level difference (ILD) between the leading tone and the contiguously trailing tone. The trailing tone was at $70 \mathrm{~dB}$ SPL, whereas the leading tone could be at 76 or $64 \mathrm{~dB}$ SPL. In the pattern $280-240 \mathrm{msec}$, for which Sasaki et al. (1993) found the biggest overestimation ( $29 \mathrm{msec}$ ), Ueda and Ohtsuki indeed established an overestimation of $32 \mathrm{msec}$ of the second tone when the first tone was $76 \mathrm{~dB}$, but they also established an overestimation of $28 \mathrm{msec}$ when the first tone was $64 \mathrm{~dB}$; these overestimations did not differ significantly from each other. Hence, Ueda and Ohtsuki argued that Sasaki et al.'s surmise that Warren et al.'s (1972) potential masker rule could explain the illusory lengthening was wrong. Ueda and Ohtsuki discussed (but rejected) another explanation of the lengthening of the second tone: that the second tone of $240 \mathrm{msec}$ might have been assimilated to the duration of the first tone of $280 \mathrm{msec}$. The authors concluded that neither Warren's rule nor duration assimilation could explain the overestimation of the filled $t_{2}$ durations, a new illusion for which we coin the term time stretching. ${ }^{1}$

Two unpublished studies (Bakker, Balabanova, van Bommel, Hovers, \& Vlasblom, 1994; Simons, 1995) carried out slightly before Ueda and Ohtsuki (1996) in the laboratory of G.t.H. support the results of the latter study.
Because neither study is easily accessible, we discuss them in slightly more detail than usual. Bakker et al. presented a stimulus pattern in which a 200-msec band noise between 900 and $2000 \mathrm{~Hz}$ immediately preceded a standard 200 -msec sine tone. The standard sine tone could be 900 , 1342 , or $2000 \mathrm{~Hz}$, and the intensity level of the band noise was 0,5 , or $10 \mathrm{~dB}$ higher than that of the sine tone. In both the experimental (band noise-sine tone) and control (sine tone presented solely) trials, a comparison sine tone followed after a silent interval of a random duration lasting between 500 and 1,000 msec. Participants were confronted with the method of constant stimuli. The duration of the comparison sine tone varied from 80 to $320 \mathrm{msec}$ in 15 -msec steps, and 17 comparison values were randomly paired with the standard sine tone. From the percentages of judgments "shorter/longer" than the standard, the PSEs were calculated for the experimental (exp) and the control (con) trials. The results showed that the overestimation ( $\mathrm{PSE}_{\text {exp }}-\mathrm{PSE}_{\mathrm{con}}$ ) was not much affected by intensitylevel conditions or by frequency relations between neighboring sounds (see Table 1).

Simons (1995) presented stimuli consisting of a 1,000msec 1/3-octave band noise located around $1 \mathrm{kHz}$ in logarithmic frequency, followed immediately by a $200-\mathrm{msec}$ standard sine tone (note that possible assimilation was avoided by the choice of very different durations between the noise and the tone). The standard sine tones were 500, 1000 , and $1600 \mathrm{~Hz}$, and the ILDs between the band noise and the sine tone were 6,0 , and $-6 \mathrm{~dB}$. The participants were required to adjust the duration of a comparison sine tone, presented 3,000 msec after the standard sine tone. In the control condition, a comparison sine tone followed the standard sine tone, which was not preceded by a band noise. When the band noise was $6 \mathrm{~dB}$ more intense, Simons found a $30-\mathrm{msec}$ overestimation of the $200-\mathrm{msec} 1-\mathrm{kHz}$ tone. This overestimation was significant; note the striking similarity of the amount of overestimation, $30 \mathrm{msec}$, to the overestimations of $29 \mathrm{msec}$ reported by Sasaki et al. (1993) and $32 \mathrm{msec}$ reported by Ueda and Ohtsuki (1996). When the band noise and the tone had equal intensity (the $0-\mathrm{dB}$ condition), Simons found a significant overestimation of $20 \mathrm{msec}$ of the $200-\mathrm{msec}$ tone. Even when the tone was $-6 \mathrm{~dB}$ with respect to the band-noise intensity level, Simons found a small but significant overestimation of $5 \mathrm{msec}$. The same pattern of diminishing overestimations from 6 to 0 to $-6 \mathrm{~dB}$ was found when the sine tone was $500 \mathrm{~Hz}$ (from 15 to 11 to $5 \mathrm{msec}$, all three values being

Table 1

Results of Bakker et al. (1994): Experimental and Control Points of Subjective Equality (PSEs) in Milliseconds As a Function of the Intensity-Level Difference Between Band Noise and Sine Tone, Dependent on Sine-Tone Frequency

\begin{tabular}{lrrrrrrrrr}
\hline & \multicolumn{9}{c}{ Intensity-Level Difference } \\
\cline { 2 - 10 } & \multicolumn{3}{c}{$0 \mathrm{~dB}$} & \multicolumn{3}{c}{$5 \mathrm{~dB}$} & \multicolumn{3}{c}{$10 \mathrm{~dB}$} \\
\hline Sine-tone frequency (Hz) & 900 & 1342 & 2000 & 900 & 1342 & 2000 & 900 & 1342 & 2000 \\
PSE $_{\text {exp }}$ (msec) & 240 & 237 & 224 & 247 & 236 & 233 & 249 & 232 & 236 \\
PSE $_{\text {con }}$ (msec) & 208 & 199 & 202 & 208 & 199 & 202 & 208 & 199 & 202 \\
Duration overestimation (msec) $^{3}$ & 32 & 38 & 22 & 39 & 37 & 31 & 41 & 33 & 34 \\
\hline
\end{tabular}

Note-The duration overestimations of the $200-\mathrm{msec}$ sine tone are the differences between the experimental and control PSEs (PSE exp - PSE $_{\mathrm{con}}$ ). 
significant) and when it was $1600 \mathrm{~Hz}$ (from 22 to 13 to $-2 \mathrm{msec}$, the first two values being significant). Bakker et al.'s (1994) and Simons's results support Ueda and Ohtsuki's study. The results of Sasaki et al. (1993) and Ueda and Ohtsuki, applying homophonic (tone-tone) patterns, and those of Bakker et al. and Simons, applying heterophonic (band noise-tone) patterns, also converge rather well numerically.

An explanation of the results of these four studies in terms of Warren et al.'s (1972) potential masker rule would seem implausible, because (1) the stimulus patterns had not even the necessary minimum configuration (faint sound-loud sound-faint sound) to make Warren's rule work, (2) overestimations were also found, even when the preceding tone or noise was less intense than the standard sine tone to be judged for duration. A clue to an alternative explanation is Bregman's (1990) argument regarding the continuity illusion, that the louder sound might also actually mask the offset and onset of the interrupted fainter sound. In case of the stimuli used in the four studies we have discussed (tone-tone and band-noise-tone patterns), Bregman's argument pertains to forward masking of the onset of the standard sine tone by the preceding tone or band noise. We hypothesize that actual forward masking obscured the onset of the tone, which has to be restored perceptually to make possible the duration judgment of the tone.

Our Web site ${ }^{2}$ contains an audio demonstration with a stimulus similar to those used by Simons (1995). An $800-\mathrm{Hz}$ tone lasting $200 \mathrm{msec}$ is preceded immediately by a $1,000-$ msec band noise from 400 to $1600 \mathrm{~Hz}$. After $1,500 \mathrm{msec}$, this heterophonic pattern is followed solely by the $800-\mathrm{Hz}$, 200-msec tone, the duration of which appears to be clearly shorter than the same tone that was preceded by the band noise. The demo also contains a control condition in which the tone is presented alone twice, and both instances sound equally long. Besides the experimental band-noise-tone pattern demonstrating a clear illusory lengthening of the tone, one can also hear that the tone starts before the band noise stops. Such a too-early apparent onset reminds us of studies by Wrightson and Warren (1981) and Warren, Bashford, Healy, and Brubaker (1994).

Wrightson and Warren (1981) reported evidence for illusory lengthening of the fainter tone in the paradigm of repetitive alternation. In their study, a 70-dB sine tone lasting $1,000 \mathrm{msec}$, alternating with an $80-\mathrm{dB}$ band noise lasting $500 \mathrm{msec}$, had to be judged for apparent onset and offset times. When the tone frequency was within the frequency edges of the band noise, the apparent onset was too early by $101 \mathrm{msec}$, whereas the apparent offset was too late by $112 \mathrm{msec}$. Given that the task of matching onsets and offsets of the fainter sound measures the same thing as a direct estimation or adjustment of its duration, the duration of the 1,000-msec tone in Wrightson and Warren's study was overestimated by 213 msec.

Whereas Wrightson and Warren (1981) measured apparent onsets and offsets and deduced illusory lengthening of the fainter tone from these values, Warren et al. (1994) straightforwardly established the apparent dura- tion of the fainter tone by the method of adjustment. They reported increases in the apparent duration of the fainter tone (the inducee), when alternated with a tone of higher intensity (the inducer). The inducer was a $70-\mathrm{dB}, 1-\mathrm{kHz}$ sine tone, and the inducee was a 66- $\mathrm{dB}$ sine tone, varying between nine frequency values (one was $1 \mathrm{kHz}$, and the other eight frequencies were $1,2,6$, and 10 semitones higher or lower). Both the inducer and the inducee lasted $200 \mathrm{msec}$. It was established that the subjective duration of the 1-kHz inducee was $400 \mathrm{msec}$ - that is, it continued completely behind the inducer. Incomplete continuity was found for the other frequencies. The subjective durations of the inducees were significantly longer than were their baseline subjective durations (measured in absence of the inducer), except for frequencies that were 6 and 10 semitones lower than $1 \mathrm{kHz}$. It was found that the closer the frequencies of inducer and inducee were to one another, the larger the duration overestimation of the inducee became, in particular when the frequency of the inducee was higher. In sum, in addition to complete temporal induction when the frequencies of the louder and fainter sine tones were both $1 \mathrm{kHz}$, we have examples of incomplete temporal induction in the Warren et al. (1994) study. With all respect for the long-standing creative and productive work of the Warren group, we strongly surmise that the phenomenon of incomplete temporal induction is rather the result of actual forward and backward masking of onsets and offsets and might not be related to classic illusory auditory continuity for which potential simultaneous masking seems to be a plausible explanation.

Our aim in the present study was to extend our knowledge of the process underlying time stretching. We increased the duration of the trailing sine tone well beyond the relatively short durations $(80-280 \mathrm{msec})$ applied in previous experiments: $200-800 \mathrm{msec}$ in Experiment 1 and $100-800 \mathrm{msec}$ in Experiment 2. We varied ILD in Experiments 1 and 5 . The frequency relation between the sine tone and preceding band noise, expressed as octave difference, was varied in Experiment 2. The duration of the preceding band noise was varied in Experiment 3. We inspected the effect of inserting silent gaps of increasing duration between band noise and sine tone in Experiment 4. Finally, in Experiment 5 we examined whether the use of nonfrozen band noise yields patterns of time stretching similar to those of frozen band noise. In the General Discussion, we attempt to show that the auditory-continuity and time-stretching illusions, despite their different perceptual processing origins, both can be understood in the framework of Nakajima et al.'s (2000) "event construction model," which is being developed as a general theory subsuming the auditory grammar already proposed in 1996 (Nakajima, 1996; Nakajima \& Sasaki, 1996). We also attempt to analyze how time stretching interacts with such classic phenomena as temporal contrast and assimilation.

\section{EXPERIMENT 1}

The durations of the standard sine tones used in Sasaki et al. (1993), Ueda and Ohtsuki (1996), Bakker et al. 
(1994), and Simons (1995) were relatively short, and their ranges were rather restricted. The maximum duration overestimation in these four experiments was about $30 \mathrm{msec}$. A pilot experiment in G.t.H.'s laboratory, using $1-\mathrm{kHz}$ standard sine-tone durations of 200,400 , and $600 \mathrm{msec}$, showed that their respective overestimations increased from 40 to 85 to $90 \mathrm{msec}$ when the preceding 1/3-octave band noise, lasting $1,000 \mathrm{msec}$, was $6 \mathrm{~dB}$ more intense, and the respective overestimations increased from 30 to 65 to $85 \mathrm{msec}$ when band noise and sine tone had equal intensity ( $0-d B$ ILD). Even when the band noise was $-6 \mathrm{~dB}$ (less intense than the sine tone), respective overestimations increased from 15 to 20 to $35 \mathrm{msec}$ for tone durations of 200,400 , and $600 \mathrm{msec}$. In the present experiment, we decided to add tone durations of 300,500 , and $800 \mathrm{msec}$ to the pilot values of 200,400 , and $600 \mathrm{msec}$ and to keep the same ILDs $(-6,0$, and $6 \mathrm{~dB})$.

\section{Method}

Participants. Five individuals, 1 female and 3 male Leiden University students and G.t.H., participated. All had normal hearing according to a screening with a pure-tone audiometer. Two of the students were paid for their participation; the other 2 received curriculum credits. G.t.H. did not get bonuses.

Stimuli and Design. A 1/3-octave band noise with a $1-\mathrm{kHz}$ center frequency was sampled from Audio Test CD-1 produced by the Japan Audio Society, which we edited using sound software (GoldWave, version 3.2) in such a manner that it had a duration of $1,000 \mathrm{msec}$, including linearly ramped rise and fall times of $10 \mathrm{msec}$. Six sine tones of $1 \mathrm{kHz}$ were generated and edited with GoldWave, so that they had durations of $200,300,400,500,600$, and $800 \mathrm{msec}$, including linearly ramped rise and fall times of $10 \mathrm{msec}$. Next, the band noise and sine tones, which had a sample frequency of $22.05 \mathrm{kHz}$ and a resolution of 16 bits, were exported to MATLAB, the software that was used to run the online experiment. The band noises and the sine tones were further edited in MATLAB Professional (version 4.2, including the Signal Processing Toolbox [version 1.0], which produced 16-bit samples at $44.1 \mathrm{kHz}$ ) such that the SPL of the band noises was $-6,0$, or $6 \mathrm{~dB}$ relative to the SPL of the sine tones.

In the experimental condition, the sine tones were directly preceded by the band noise, and in the control condition, the tones were presented singly. Both the experimental and control stimuli were followed by a comparison sine tone $\left(C_{\mathrm{ST}}\right)$ after an interstimulus interval (ISI) of $2,000 \mathrm{msec}$. For the $200-$ and $300-\mathrm{msec}$ duration conditions, the initial duration of $C_{\mathrm{ST}}$ varied randomly from the base duration (200 or $300 \mathrm{msec}$ ) in the range $\pm(130-170) \mathrm{msec}$, in steps of $10 \mathrm{msec}$. For the 400 - and $500-\mathrm{msec}$ duration conditions, the initial length of $C_{\mathrm{ST}}$ varied randomly from the base duration by $\pm(230-270) \mathrm{msec}$, in steps of $10 \mathrm{msec}$. For the 600 - and $800-\mathrm{msec}$ duration conditions, the initial $C_{\mathrm{ST}}$ varied randomly from the base duration by $\pm(330-370) \mathrm{msec}$, in steps of $10 \mathrm{msec}$.

Procedure and Apparatus. The participants had to match the duration of $C_{\mathrm{ST}}$ to that of the standard sine tone $\left(S_{\mathrm{ST}}\right)$ by the method of adjustment. As described in the Stimuli and Design section, the initial value of $C_{\mathrm{ST}}$ varied between trials and was either clearly shorter than $S_{\mathrm{ST}}$ (ascending trials, half of the trials) or clearly longer than $S_{\mathrm{ST}}$ (descending trials, half of the trials). For both the experimental and control stimuli, there were three replications of which every first replication was regarded as training, not to be included in the analysis. There were 144 trials: 4 (3 SPL differences plus a control) $\times 6$ (tone durations) $\times 2$ (ascending/descending) $\times 3$ (replications). The 144 trials were randomized and were then divided over four sessions containing 36 trials each. A session lasted about $1 \mathrm{~h}$, with an obligatory 10 -min break at the midpoint.

The participants were seated in a sound-attenuating booth in front of a computer screen that showed a horizontal slider bar in the mid- dle of the screen and a slider button positioned midway along the bar. The words SHORTER, PRESENT, and LONGER were positioned over the left end, center, and right end of the slider bar. A button displaying the word NEXT was positioned in the lower left-hand comer of the screen. To hear the initial trial, the participant clicked the slider button with the mouse pointer. After having heard the initial trial, the participant could start adjusting $C_{\mathrm{ST}}$ by moving the slider button to the left to shorten $C_{\mathrm{ST}}$ or by moving it to the right to lengthen $C_{\mathrm{ST}}$. After each adjustment, the slider button automatically jumped back to the middle position, with the newly adjusted duration of $C_{\mathrm{ST}}$ as its reference point, ensuring that participants received no visual duration clues. After each presentation of the stimulus, $C_{\mathrm{ST}}$ could be adjusted in steps as small as $1 \mathrm{msec}$ up to as much as $200 \mathrm{msec}$ per presentation. The maximum adjustable duration of $C_{\mathrm{ST}}$ was $1,500 \mathrm{msec}$, and the minimum one was $20 \mathrm{msec}$. Participants were allowed to hear as many presentations as they thought necessary, and at each new presentation they heard $S_{\mathrm{ST}}$ and the most recently adjusted $C_{\mathrm{ST}}$. When confident that $S_{\mathrm{ST}}$ and $C_{\mathrm{ST}}$ sounded equally long, they could click the NEXT button to trigger the next trial. The PSE resulting from each trial was registered by the computer program.

Presentation of the stimuli and data collection were controlled by a program written in MATLAB running on an IBM-compatible computer with a Sound Blaster AWE32 sound card. The signals were led through a 31-band graphic equalizer (Maruei Electric Co., MEQ-3100), an amplifier (JVC AX211), and headphones (JVC HA-D500). The settings of the graphic equalizer were such that frequencies below $400 \mathrm{~Hz}$ and above $4000 \mathrm{~Hz}$ were attenuated by $15 \mathrm{~dB}$, to prevent possible high- and low-frequency distortions. Frequencies between 400 and $4000 \mathrm{~Hz}$ were not attenuated. A random sample of stimuli was recorded with a DAT recorder (JVC XD-Z505) for duration calibration purposes. Duration calibration was deliberately performed on a totally different system-a Commodore Amiga 2000, using Microdeal MegaloSound sampling software. SPL differences were calibrated with a precision sound-level meter (Brüel \& Kjaer 2203) mounted with an artificial ear (Brüel \& Kjaer 4152) and a microphone (Brüel \& Kjaer 4144). The audiometric testing of the participants was done with a pure-tone audiometer (Madsen Screening Digital, DSA6214).

\section{Results and Discussion}

The results-that is, the PSEs in the experimental and control conditions and their differences-are given in Table 2. We first tested whether the overestimations (the $\mathrm{PSE}_{\text {exp }}-\mathrm{PSE}_{\mathrm{con}}$ values) were significant. At each combination of ILD and tone duration, we did a paired $t$ test (two-tailed), and it turned out that all overestimations at 0 and $6 \mathrm{~dB}$ were significant. At $-6 \mathrm{~dB}$, only the overestimations of the 500 - and $600-\mathrm{msec}$ tone durations were significant. Figure 3 shows the mean overestimations and their standard errors dependent on ILD and tone duration. Overestimations increased with increasing ILD. For all three ILDs, a steep increase of overestimations can be seen from 200 to $500 \mathrm{msec}$, and a decrease can be seen from 600 to $800 \mathrm{msec}$.

We averaged the overestimations over ascending/ descending trials and over replications, and we submitted those averages (of $2 \times 2=4$ observations per participant per condition) to a 3 (SPL differences) $\times 6$ (tone durations) $\times 5$ (participants) repeated measures ANOVA. The main effect of ILD was significant $[F(1.385,5.539)=$ $20.5, p<.007, \eta_{\mathrm{p}}^{2}=.837$; here and later, all fractional $d f \mathrm{~s}$ are Greenhouse-Geisser corrected], and the main effect of tone duration was significant as well $[F(2.008,8.031)=$ $\left.10.65, p<.006, \eta_{\mathrm{p}}^{2}=.727\right]$. The interaction between the two factors was not significant $(p<.254)$. 
Table 2

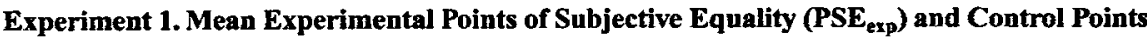
of Subjective Equality (PSE con $_{\text {) }}$ As a Function of Intensity-Level Difference (ILD $=-6,0,+6 \mathrm{~dB}$ ) and Tone Duration $(200,300,400,500,600$, and $800 \mathrm{msec})$

\begin{tabular}{|c|c|c|c|c|c|c|c|}
\hline \multirow[b]{2}{*}{ ILD } & & \multicolumn{6}{|c|}{ Standard Sine-Tone Duration (msec) } \\
\hline & & 200 & 300 & 400 & 500 & 600 & 800 \\
\hline$-6 \mathrm{~dB}$ & $\begin{array}{l}\operatorname{PSE}_{\text {exp }} \text { (msec) } \\
\text { PSE }_{\text {con }} \text { (msec) } \\
\text { Duration overestimations (msec) } \\
\quad p<\end{array}$ & $\begin{array}{l}197 \\
199 \\
-2 \\
\text { n.s. }\end{array}$ & $\begin{array}{l}293 \\
287 \\
6 \\
\text { n.s. }\end{array}$ & $\begin{array}{r}400 \\
391 \\
9 \\
\text { n.s. }\end{array}$ & $\begin{array}{r}521 \\
483 \\
38 \\
\quad .005\end{array}$ & $\begin{array}{l}648 \\
588 \\
60 \\
.0001\end{array}$ & $\begin{array}{r}807 \\
806 \\
1 \\
\text { n.s. }\end{array}$ \\
\hline $0 \mathrm{~dB}$ & $\begin{array}{l}\mathrm{PSE}_{\text {exp }} \text { (msec) } \\
\mathrm{PSE}_{\text {con }} \text { (msec) } \\
\text { Duration overestimations (msec) } \\
\quad p<\end{array}$ & $\begin{array}{c}219 \\
199 \\
20 \\
.014\end{array}$ & $\begin{array}{c}317 \\
287 \\
30 \\
.004\end{array}$ & $\begin{array}{l}429 \\
391 \\
38 \\
.007\end{array}$ & $\begin{array}{l}566 \\
483 \\
83 \\
.00001\end{array}$ & $\begin{array}{l}682 \\
589 \\
93 \\
.00001\end{array}$ & $\begin{array}{c}850 \\
806 \\
44 \\
.04\end{array}$ \\
\hline $6 \mathrm{~dB}$ & $\begin{array}{l}\mathrm{PSE}_{\text {exp }} \text { (msec) } \\
\mathrm{PSE}_{\text {con }} \text { (msec) } \\
\text { Duration overestimations (msec) } \\
\quad p<\end{array}$ & $\begin{array}{c}220 \\
199 \\
21 \\
.005\end{array}$ & $\begin{array}{r}348 \\
287 \\
61 \\
\quad .001\end{array}$ & $\begin{array}{r}466 \\
391 \\
75 \\
.00001\end{array}$ & $\begin{array}{l}585 \\
483 \\
102 \\
.00001\end{array}$ & $\begin{array}{l}694 \\
588 \\
106 \\
.00001\end{array}$ & $\begin{array}{rr}874 & \\
806 & \\
68 & \\
& .002\end{array}$ \\
\hline
\end{tabular}

Note-Duration overestimations $=\mathrm{PSE}_{\text {exp }}-\mathrm{PSE}_{\text {con }} ;$ n.s. $=$ not significant.

The major conclusions are (1) that increasing the sinetone duration beyond the values used in the four timestretching studies discussed in the introduction yielded much larger overestimations (at tone durations of 500 and $600 \mathrm{msec}$, overestimations even reached values of about $105 \mathrm{msec}$ ) and (2) that, even when the preceding band noise was equally or less intense than the sine tone, many significant overestimations were observed.

\section{EXPERIMENT 2}

In this experiment, we varied the sine tones between three frequency values and varied the center frequency of the preceding band noise between the same three values. We used all nine band-noise-sine-tone combinations. The purpose was to investigate whether the amount of overestimation of the sine-tone duration depends on the frequency relationship of band noise and sine tone. Although Simons (1995) established the presence of such a dependency, that dependency was only for short tone durations; hence, we added longer sine-tone durations here as well. Our second purpose was to replicate the finding of Experiment 1 that the amount of overestimation of the sine tone decreases for tone durations beyond $600 \mathrm{msec}$.

\section{Method}

Participants. Eight psychology students of Leiden University participated. They ranged in age from 21 to 27 years. Six were female, and two were male. Seven participants passed a pure tone audiometric screening for left and right ears. One student had a hearing

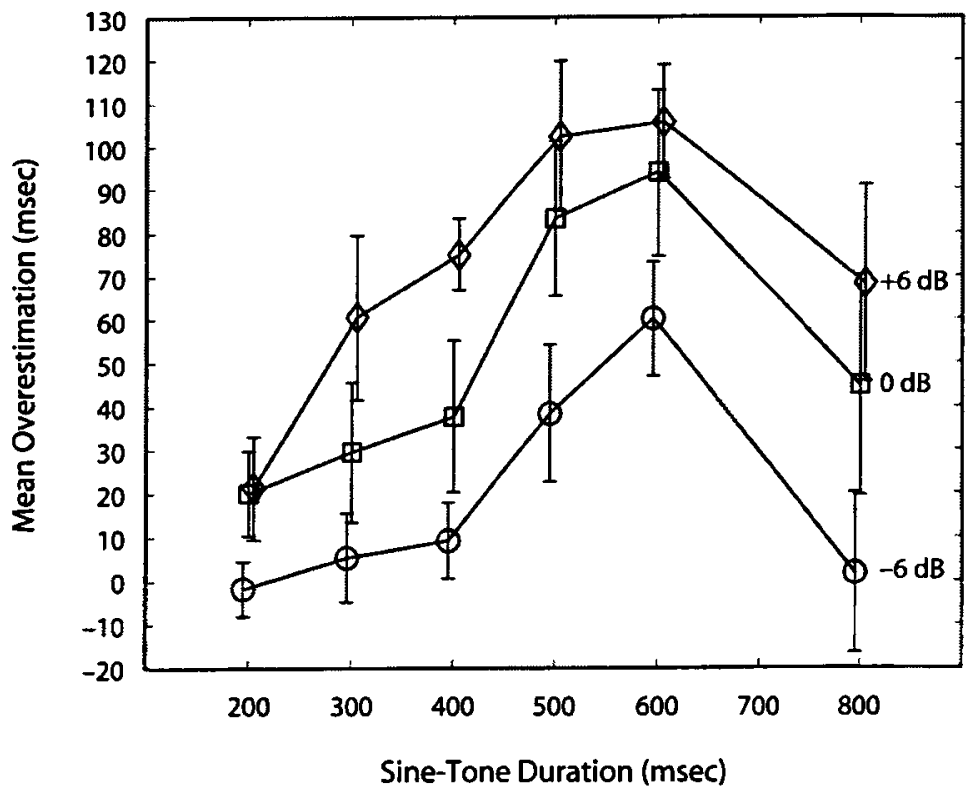

Figure 3. Experiment 1. The mean duration overestimations of the sine tone and their standard errors (vertical bars) as a function of tone duration and ILD with the preceding 1/3-octave band noise, lasting 1,000 msec. 
loss of approximately $40 \mathrm{~dB}$, but she decided to participate because the students did the experiment as a team to earn curriculum credits.

Stimuli and Design. The control stimuli were 500-, 1000-, and $2000-\mathrm{Hz}$ pure sine tones. In the experimental stimuli, these tones were immediately preceded by $1 / 3$-octave band noises centered around 500,1000 , or $2000 \mathrm{~Hz}$. The band noises had a 6-dB higher intensity than the sine tones and had a duration of $1,000 \mathrm{msec}$. The duration of the sine tones ranged between 100 and $800 \mathrm{msec}$ in $100-\mathrm{msec}$ steps. The sound stimuli were generated and presented in the same way as in Experiment 1 . In total, there were 3 (bandnoise frequencies) $\times 3$ (tone frequencies) $\times 8$ (tone durations) $=$ 72 stimuli. Because there were ascending and descending trials, we had $72 \times 2=144$ experimental trials. The control condition comprised 3 (tone frequencies) $\times 8$ (tone durations) $\times 2$ (ascending/ descending) $=48$ trials. This created a total of 192 trials for each participant (144 experimental +48 control), and, because every trial was replicated once, there were 384 trials.

Procedure and Apparatus. The task, equipment, and calibration were the same as in Experiment 1. The participants adjusted $C_{\mathrm{ST}}$ as often as necessary, until they were satisfied with the match between the durations of $S_{\mathrm{ST}}$ and $C_{\mathrm{ST}}$. The 384 trials were randomized and divided over 12 sessions. Each session contained 384/12 = 32 trials and lasted about $1 \mathrm{~h}$, with a $10-\mathrm{min}$ break given halfway.

\section{Results and Discussion}

For all nine pairings of band-noise and sine-tone frequencies, and at each level of tone duration, the amounts of overestimation were calculated by subtracting the appropriate control PSEs from the experimental PSEs for each participant. Before presenting the statistical analyses of the sine-tone overestimations, a caveat is necessary. Even though the three band-noise center frequencies $(500$, $1000,2000 \mathrm{~Hz}$ ) were crossed with the same three sinetone frequencies, yielding nine band-noise-tone patterns (500-500, 500-1000, 500-2000; 1000-500, 1000-1000, $1000-2000$; and 2000-500, 2000-1000, 2000-2000 Hz), these nine stimuli do not fit in an overall ANOVA. The reason is that, in each of the three sets with equal band-noise frequency (the $500-, 1000-$, and $2000-\mathrm{Hz}$ sets separated by semicolons in the parentheses above), the three members of each set had different levels of octave relationship between band noise and sine tone. In the $500-\mathrm{Hz}$ band-noise set, the octave differences with the sine tones were $0,+1$, and +2 ; in the $1000-\mathrm{Hz}$ set, the differences were $-1,0$, and +1 ; and in the $2000-\mathrm{Hz}$ band-noise set, the differences were $-2,-1$, and 0 . Ipso facto, we had to run three separate ANOVAs. Figure 4 depicts the mean overestimations separated with regard to band-noise frequency, and thus with regard to different sets of octave differences.

Figure 4A shows that the largest overestimations occurred when the tone trailing the band noise had the same frequency, thus $500 \mathrm{~Hz}$, and duration overestimations were smaller for the 1000 - and $2000-\mathrm{Hz}$ tones. We ran a 3 (octave difference) $\times 8$ (tone duration) $\times 2$ (ascending/ descending) $\times 2$ (replications) repeated measures ANOVA. The main effect of octave difference was not significant $(p<.121)$, but the main effect of tone duration was significant $\left[F(3.228,22.596)=14.165, p<.00003, \eta_{\mathrm{p}}^{2}=\right.$ $.669]$. The interaction between octave difference and tone duration was not significant $(p<.285)$.

Figure $4 \mathrm{~B}$ also shows that the largest overestimations occurred when the tone trailing the band noise had the same frequency, thus $1000 \mathrm{~Hz}$, and overestimations were smaller

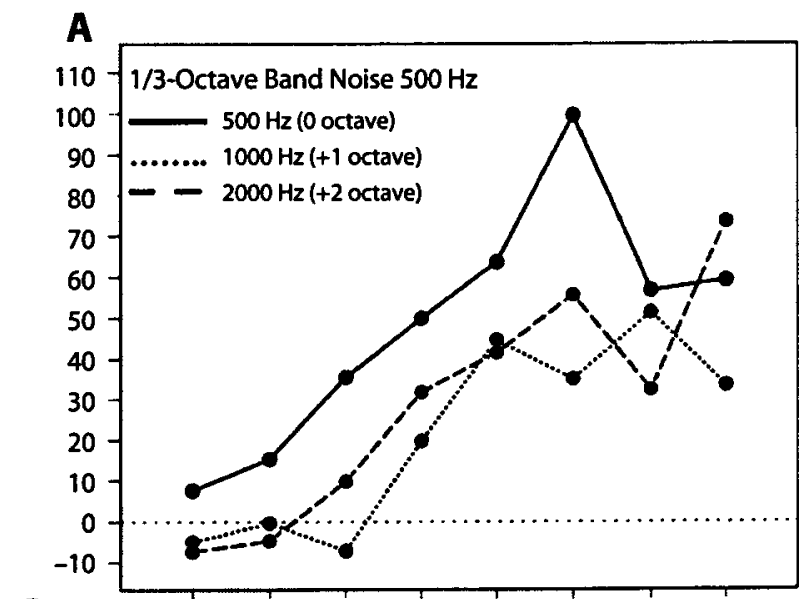

岛
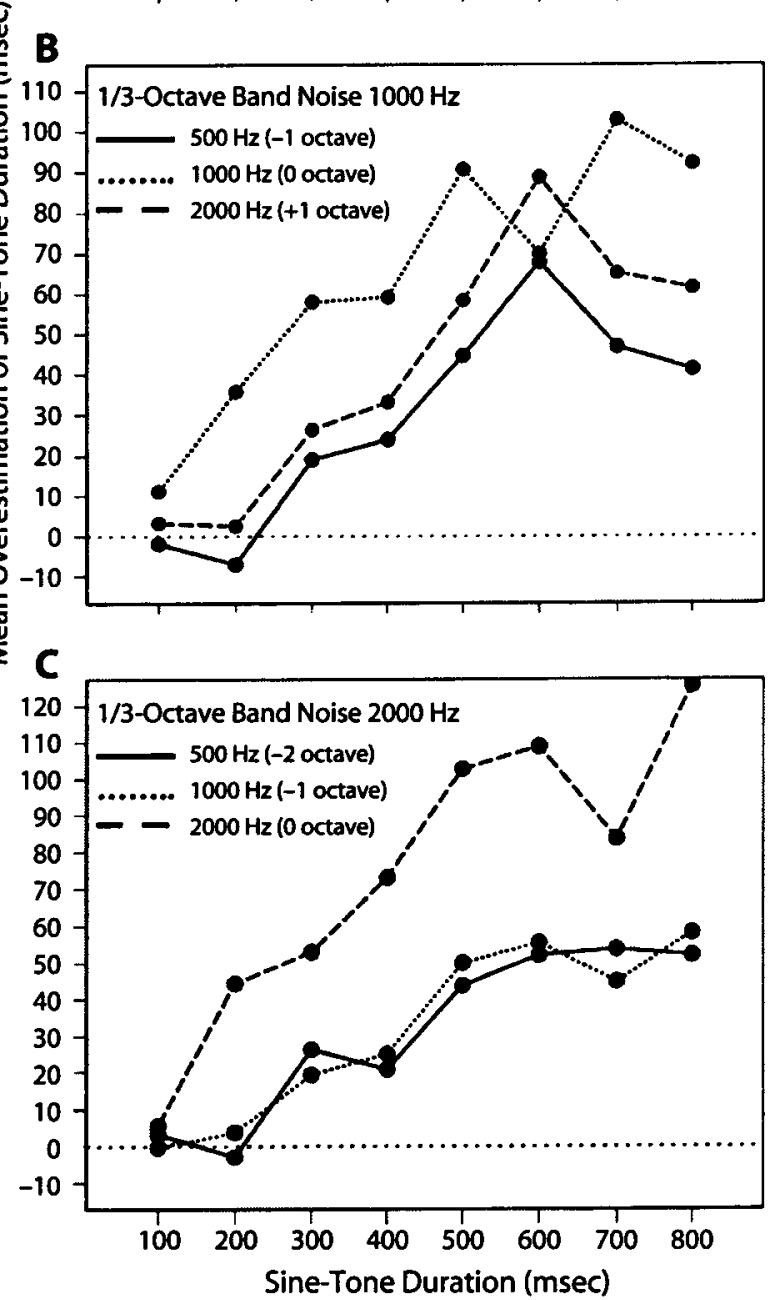

Figure 4. Experiment 2. (A) Mean duration overestimations of the sine tones as a function of tone duration and frequency difference between band noise and tone $(0,+1,+2$ octaves) when the center frequency of the preceding 1/3-octave band noise was $500 \mathrm{~Hz}$. (B) Mean duration overestimations of the sine tones as a function of tone duration and frequency difference between band noise and tone $(-1,0,+1$ octave $)$ when the center frequency of the preceding 1/3-octave band noise was $1000 \mathrm{~Hz}$. (C) Mean duration overestimations of the sine tones as a function of tone duration and frequency difference between band noise and tone $(-2,-1,0$ octaves) when the center frequency of the preceding 1/3-octave band noise was $2000 \mathrm{~Hz}$. 
for the 500- and 2000-Hz tones. The same kind of ANOVA as described above showed that the effect of octave difference was significant $[F(1.673,11.708)=7.222, p<.011$, $\left.\eta_{\mathrm{p}}^{2}=.508\right]$ and that the main effect of tone duration was also significant $[F(2.423,16.962)=13.169, p<.0005$, $\eta_{\mathrm{p}}^{2}=.653 \mathrm{]}$. The interaction between tone frequency and duration was not significant $(p<.45)$.

Figure $4 \mathrm{C}$ again shows that the largest overestimations occurred when the tone trailing the band noise had the same frequency, thus $2000 \mathrm{~Hz}$, and overestimations were smaller for the $500-$ and $1000-\mathrm{Hz}$ sine tones. The same kind of ANOVA as described above showed that the main effect of octave difference was significant $[F(1.524$, $\left.10.669)=5.656, p<.027, \eta_{\mathrm{p}}^{2}=.447\right]$, as was the main effect of tone duration $[F(3.488,24.418)=10.867, p<$ $\left..0001, \eta_{\mathrm{p}}^{2}=.608\right]$. The interaction between octave difference and tone duration was not significant $(p<.41)$.

Although the effect of octave difference failed to reach significance when the preceding band noise had a center frequency of $500 \mathrm{~Hz}$, the results of the three analyses together support the expectation that the amount of overestimation was largest when the band noise and sine tone had the same frequencies (0-octave difference). It seems that the onset of the $S_{\mathrm{ST}}$ to be judged for duration had been blurred most by forward masking of a preceding band noise of the same center frequency. Overall, there was a clear increase of overestimation when the tone duration increased up to $600 \mathrm{msec}$, as found in Experiment 1 . Beyond $600 \mathrm{msec}$, there was a tendency for overestimation to decrease but less clearly than that in Experiment 1 (cf. Figure 3). We postpone the explanation of these effects of sine-tone duration on its overestimation, similar in Experiments 1 and 2, to the general discussion.

\section{EXPERIMENT 3}

In the two previous experiments, the band-noise duration was $1,000 \mathrm{msec}$. We proposed that time stretching of the contiguously following sine tone was caused by the preceding band noise blurring the tone onset. We were interested in what would happen to the amount of overestimation when the preceding band noise was considerably shorter than $1,000 \mathrm{msec}$, and we applied a range of durations from 50 to $500 \mathrm{msec}$. We chose this range of bandnoise durations also because it covers the range of duration values of the preceding sine tones used in the homophonic sound patterns (tone-tone) in the experiments of Sasaki et al. (1993) and Ueda and Ohtsuki (1996).

It is known that the loudness of a sound is dependent on its duration when sounds get relatively very short: Loudness diminishes, therefore, with diminishing duration. However, the literature reports different estimates for the critical duration beyond which loudness is no longer dependent on intensity. Scharf and Houtsma (1986) tabulated 16 studies (chap. 15, p. 11), and critical durations varied between 15 and $500 \mathrm{msec}$. Such disparities are understandable, given the different experimental methods and different sounds used (pure tones of different frequencies, white noise, dif- ferent band noises). Because we planned 1/3-octave band noises (from 50 to $500 \mathrm{msec}$ ) and decided that their loudness should be equal, we first did an experiment to establish the iso-loudness curve for the band noises to be used, which is Experiment 3A. In Experiment 3B, the sound pressure levels corresponding to the iso-loudness curve were implemented on the band-noise durations from 50 to $400 \mathrm{msec}$ that preceded the sine tone.

\section{Experiment 3A}

\section{Method}

Participants. Seven psychology students of Leiden University served in this experiment (20-26 years of age, 1 female and 6 males). They were screened with the pure-tone audiometer mentioned above and had normal hearing. Payment was in curriculum credits.

Stimuli and Design. A stimulus consisted of a standard band noise $\left(S_{\mathrm{BN}}\right)$ and a comparison band noise $\left(C_{\mathrm{BN}}\right)$. Both band noises had a bandwidth of $1 / 3$ octave and a center frequency of $1000 \mathrm{~Hz}$. The $S_{\mathrm{BN}}$ had a 500 -msec duration (inclusive rise and fall times of $5 \mathrm{msec}$ ) and had an intensity of $76 \mathrm{~dB} \mathrm{SPL}$. The $C_{\mathrm{BN}}$, with the same rise and fall times, could have a duration of $50,100,150,200,300$, or $400 \mathrm{msec}$. Thus there were six combinations of $S_{\mathrm{BN}}$ and $C_{\mathrm{BN}}$. Each stimulus was presented eight times, divided over two blocks. Within one block, $S_{\mathrm{BN}}$ followed $C_{\mathrm{BN}}$ after $2,000 \mathrm{msec}$, and within the other block, $C_{\mathrm{BN}}$ followed $S_{\mathrm{BN}}$ after $2,000 \mathrm{msec}$. In two out of four stimulus presentations (one block), the initial sound intensity of $C_{\mathrm{BN}}$ was considerably higher, and, in the other two times, the initial sound intensity of $C_{\mathrm{BN}}$ was considerably lower than the intensity of $S_{\mathrm{BN}}$. Within a block, the four stimuli were presented randomly. This resulted in $8 \times 6=48$ trials, which were divided across two sessions. Before the experimental sessions began, each participant was given a 24-trial training session.

Procedure and Apparatus. The task consisted of adjusting the sound intensity of $C_{\mathrm{BN}}$ to that of $S_{\mathrm{BN}}$ until they were experienced as equal in loudness. The stimuli were generated using an IBMcompatible computer with a Turtle Beach MultiSound soundcard, under control of MATLAB Professional 5.0 with the Signal Processing Toolbox, which together produced 16-bit samples at $44.1 \mathrm{kHz}$. The signals were passed through an amplifier (Sony TA-FE700E) and headphones (Beyer Dynamic DT990) for presentation to both ears. Intensity and duration calibration was similar to that described in Experiment 1.

Participants were seated in front of a computer screen that showed a horizontal slider bar and a slider button positioned in the middle. Over the left-hand side of the slider bar, the words DECREASE LOUDNESS appeared, and over the right-hand side, the words INCREASE LOUDNESS appeared. A button displaying the word START in the lower right-hand corner of the screen displayed to NEXT after being pressed and to FINISHED to indicate the last trial. A PLAY SOUND button was positioned in the lower left-hand comer of the screen.

To hear the initial trial, participants clicked the START button, at which point the experiment began and the START button was replaced by the NEXT button. After having heard the initial trial, a participant could start adjusting $C_{\mathrm{BN}}$ by moving the slider button to the left, thus softening $C_{\mathrm{BN}}$, or moving it to the right, thus making it louder. After each adjustment, the slider button automatically returned to the middle position, with the newly adjusted $C_{\mathrm{BN}}$ band-noise intensity as its reference point, ensuring that subjects did not receive any visual clues about the intensity of $C_{\mathrm{BN}}$. Participants could adjust $C_{\mathrm{BN}}$ in steps as small as $0.03 \mathrm{~dB}$ to as much as $3 \mathrm{~dB}$ per presentation and were allowed to hear as many presentations as they thought necessary by pressing the PLAY SOUND button. When they were confident that $C_{\mathrm{BN}}$ sounded equally as loud as $S_{\mathrm{BN}}$, they had to push the NEXT button to move to the next trial. The PSE resulting from each trial was registered by the computer program. There was a break after each set of 12 trials. The experiment took place in a sound-attenuating booth. 


\section{Results}

The mean PSE values for the loudness of band-noise durations of $50,100,150,200,300$, and $400 \mathrm{msec}$ are displayed in Figure 5 with the standard $76 \mathrm{~dB}$ SPL of the 500 -msec band-noise duration. There was an almost linear decrease of sound intensity from 50 to $300 \mathrm{msec}$. We fitted a linear regression line (the dashed line), through the observed $\mathrm{dB}$ values at $50,100,150,200$, and $300 \mathrm{msec}$; its equation is $\mathrm{dB}_{\text {estimated }}=78.35-.007 \times$ band-noise duration $\left(R^{2}=.957\right)$. Figure 5 shows that the critical duration for loudness with the present stimuli (1/3-octave band noises around $1000 \mathrm{~Hz}$ with rise and fall times of $5 \mathrm{msec}$ ) is about $320 \mathrm{msec}$ (the intersection of the dashed line with the 76-dB level).

\section{Experiment 3B}

\section{Method}

The participants were the same ones who served in Experiment 3A. An experimental stimulus consisted of a 1/3-octave band noise, immediately followed by a $70-\mathrm{dB}, 1000-\mathrm{Hz}$ sine tone of either 300 or $700 \mathrm{msec}$. The band-noise durations were $50,100,150,200,300,400$, and $500 \mathrm{msec}$. The intensity of the $500-\mathrm{msec}$ band noise was $76 \mathrm{~dB}$ SPL, and the shorter band noises had the observed intensities established in Experiment 3A. The control condition consisted of 70-dB, $1000-\mathrm{Hz}$ sine tones only, which we called the 0 -msec band-noise condition. This resulted in 8 (band-noise durations) $\times 2$ (tone durations) $=$ 16 patterns, of which the $S_{\mathrm{BN}}$ duration had to be matched by the $C_{\mathrm{BN}}$ duration, both ascendingly and descendingly; thus a block contained 32 randomized trials. Participants did the block four times, the 32 trials randomized differently, one block per session. The first session was considered to be a training session; thus, the design was 8 (bandnoise duration) $\times 2$ (tone duration) $\times 2$ (ascending/descending) $\times$ 3 (replications). The procedure was the same as in Experiments 1 and 2, and the apparatus the same as in Experiment 3A.

\section{Results and Discussion}

All differences between the $\mathrm{PSE}_{\text {exp }}$ and $\mathrm{PSE}_{\text {con }}$ valuesthat is, the amounts of overestimation-were highly sig- nificant as tested by paired-sample $t$ tests. We mention only the $t$ tests for the shortest band-noise duration of $50 \mathrm{msec}$. For the tone duration of $300 \mathrm{msec}$, we found that its overestimation was $40 \mathrm{msec}[t(41)=4.303, p<.0001$, two tailed]. For the $700-\mathrm{msec}$ tone duration, we found that its overestimation was $48 \mathrm{msec}[t(41)=4.096, p<.0002$, two tailed]. The overestimations at the longer band-noise durations were all bigger and significant. It is remarkable that, even with the shortest band noise of $50 \mathrm{msec}$, such significant and big overestimations were established. The fact that a very short band noise gives rise to considerable overestimation supports our conviction that the process required for time stretching is that the tone onset be blurred by the presence of a preceding sound and be restored perceptually to make duration judgments possible.

Figure 6 shows the mean overestimations and their standard errors as a function of band-noise and tone durations. Up to a 300-msec band-noise duration, there was no significant difference between the overestimations of the 300- and 700-msec tone durations, but beyond a 300-msec band-noise duration, there was a dissociation: The overestimations of the $300-\mathrm{msec}$ sine-tone duration remained the same (100 msec), whereas those of the $700-\mathrm{msec}$ tone kept increasing to $150 \mathrm{msec}$. The overestimations were submitted to a 7 (band-noise duration) $\times 2$ (tone duration) $\times 2$ (ascending/descending) $\times 3$ (replications) repeated measures ANOVA. The main effect of band-noise duration was significant $[F(2.571,15.428)=16.77, p<$ $\left..00015, \eta_{\mathrm{p}}^{2}=.737\right]$. The main effect of tone duration just failed to reach significance $(p<.054)$, but the interaction between both factors was significant $[F(2.429,14.575)=$ 4.73, $\left.p<.021, \eta_{\mathrm{p}}^{2}=.441\right]$.

We applied heterophonic patterns (band noise-tone) to establish the amount of overestimation, whereas Sasaki et al. (1993) and Ueda and Ohtsuki (1996) had applied homophonic patterns (tone-tone). A problem was that time

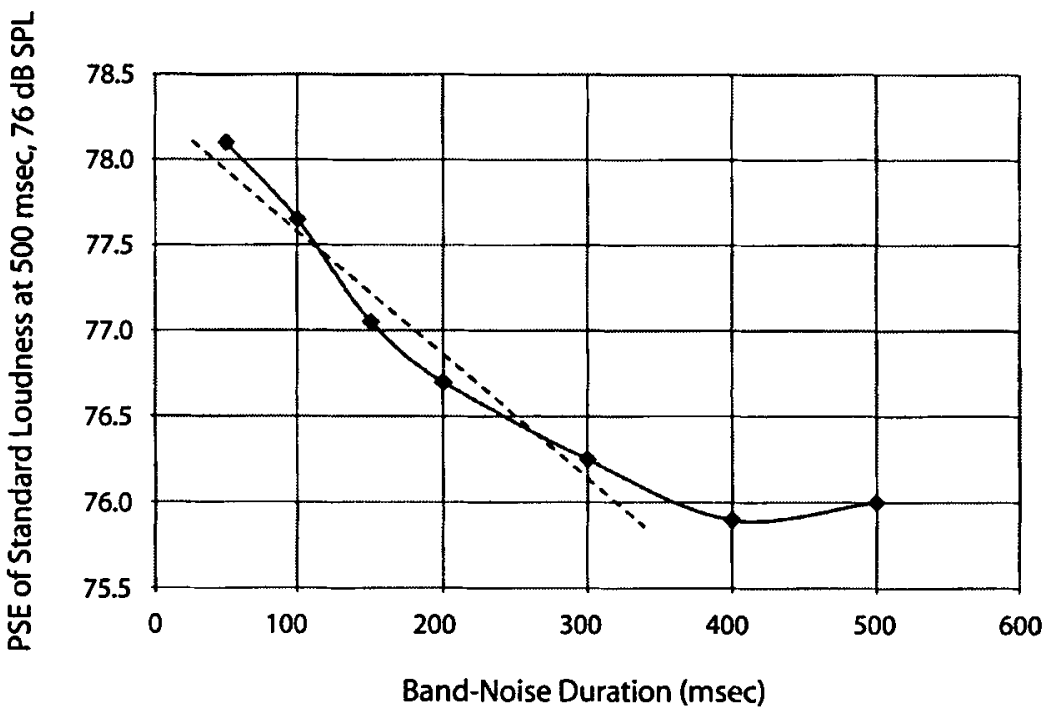

Figure 5. Experiment 3A. Mean points of subjective equality (PSEs) of the loudness of the 500-msec standard band-noise duration (76 dB SPL) for band-noise durations of $50,100,150,200,300$, and 400 msec. The inserted dashed line represents the linear fit through the $\mathrm{dBs}$ at 50, 100, 150, 200, and $300 \mathrm{msec}$ (see text for its equation). 


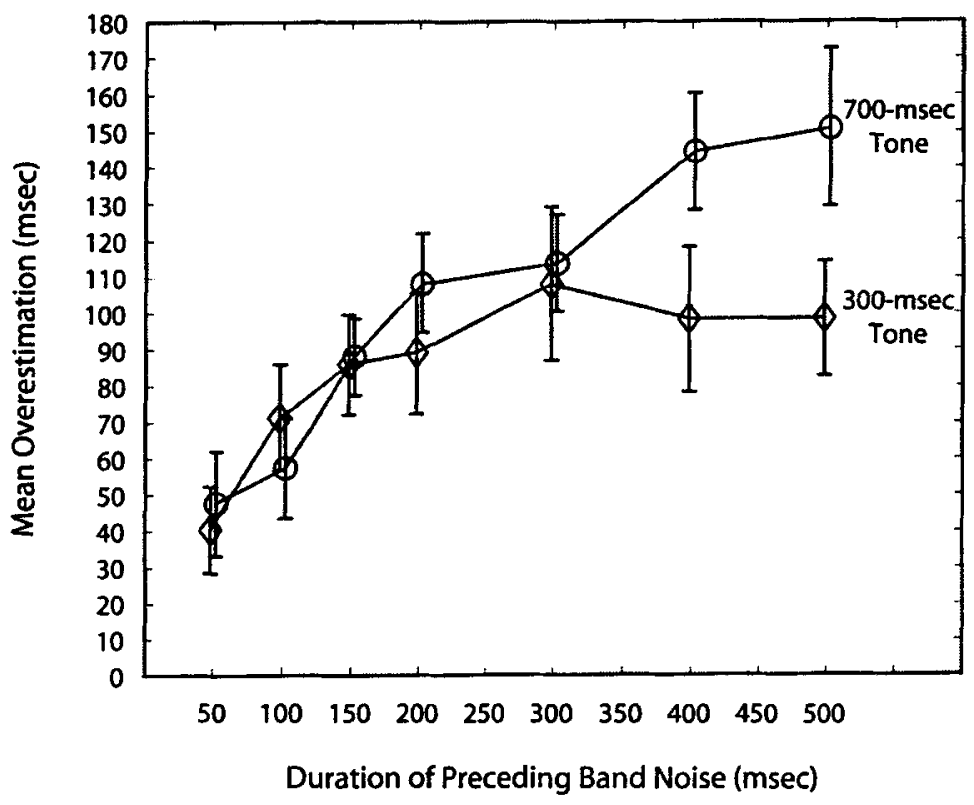

Figure 6. Experiment 3B. Mean overestimations of the sine-tone durations and their standard errors (vertical bars) as a function of tone duration and the duration of the preceding band noise.

stretching did not seem to take place in these two studies when the preceding tone was as short as $80 \mathrm{msec}$ in their homophonic patterns, but did take place when the preceding noise was as short as 50 and $100 \mathrm{msec}$ in the present heterophonic patterns. One reason for this difference might be that the onset of the trailing tone is not blurred easily in homophonic patterns, because this onset causes an audible spectral splatter, which makes its temporal position clearer perceptually. This should reduce the degree of time stretching in any condition, and the illusion can even disappear when its degree is already small. Despite this difference between homophonic and heterophonic patterns, in both cases, there was a monotonic increase of overestimation when the preceding tone or band noise increased from 80 to $280 \mathrm{msec}$ or from 50 to $300 \mathrm{msec}$, respectively (compare Figures 2 and 6). We postpone the explanation of the effect of band-noise duration on the sine-tone overestimations until the General Discussion.

\section{EXPERIMENT 4}

Warren et al. (1972) reported homophonic continuity in a recycling sequence of three band noises (all one octave wide) at 60,70 , and $80 \mathrm{~dB}$, each lasting $300 \mathrm{msec}$. The 60- $\mathrm{dB}$ band noise appeared to be on continuously. However, when silent gaps of $50 \mathrm{msec}$ were inserted between the band noises, the apparent continuity disappeared. Similar results have been found by Bregman and Dannenbring (1977). Although explanatory thinking in the present study about time stretching is in terms of forward masking rather than in terms of Warren's explanation of the continuity illusion, we thought it would be fruitful to borrow the paradigm of inserting silent gaps. We hypoth- esized that inserting silent gaps of increasing duration between the band noise and sine tone would diminish time stretching rapidly when the gap size was increased.

\section{Method}

The experiment was again steered by a program in MATLAB, and all noises and tones were generated and shaped to have $10-\mathrm{msec}$ rise and fall times. The 1/3-octave band noise, with a center frequency of $1000 \mathrm{~Hz}$, lasted $500 \mathrm{msec}$. The $1000-\mathrm{Hz}$ sine tones had durations of 100 to $800 \mathrm{msec}$ in $100-\mathrm{msec}$ steps. Between the band noise and the sine tone were gaps of six sizes: 0 (control), 10, 20,30, 40 and $50 \mathrm{msec}$. Thus, there were 192 trials [6 (gap sizes) $\times 8$ (tone durations) $\times 2$ (ascending/descending) $\times 2$ (replications) $]$ and 32 control trials [ 8 (tone durations) $\times 2$ (ascending/descending) $\times$ 2 (replications)], in which the duration of the tones presented singly had to be adjusted by $C_{\mathrm{ST}}$. Each of the 4 participants, 3 students and author G.t.H., did the 224 trials in four sessions. The procedure and equipment were the same as in the previous experiments.

\section{Results and Discussion}

Figure 7 shows that, with a 10-msec gap, time stretching had already diminished considerably and that, with a 20 -msec gap, it was almost nullified. We submitted the overestimations to a 6 (gap size) $\times 8$ (tone duration) $\times$ 2 (ascending/descending) $\times 2$ (replications) repeated measures ANOVA, which showed that the main effect of gap size was significant $[F(2.166,6.497)=91.52, p<$ $\left..000032, \eta_{\mathrm{p}}^{2}=.968\right]$. Because neither the main effect of tone duration nor the interaction between gap size and tone duration were significant $(p<.50$ and $p<.23$, respectively), we plotted time stretching as a function of gap size averaged over tone durations. We conclude that there was a release from forward masking, causing a blurred tone onset, when band noise and tone were separated by a silent 10- to 20-msec gap. 


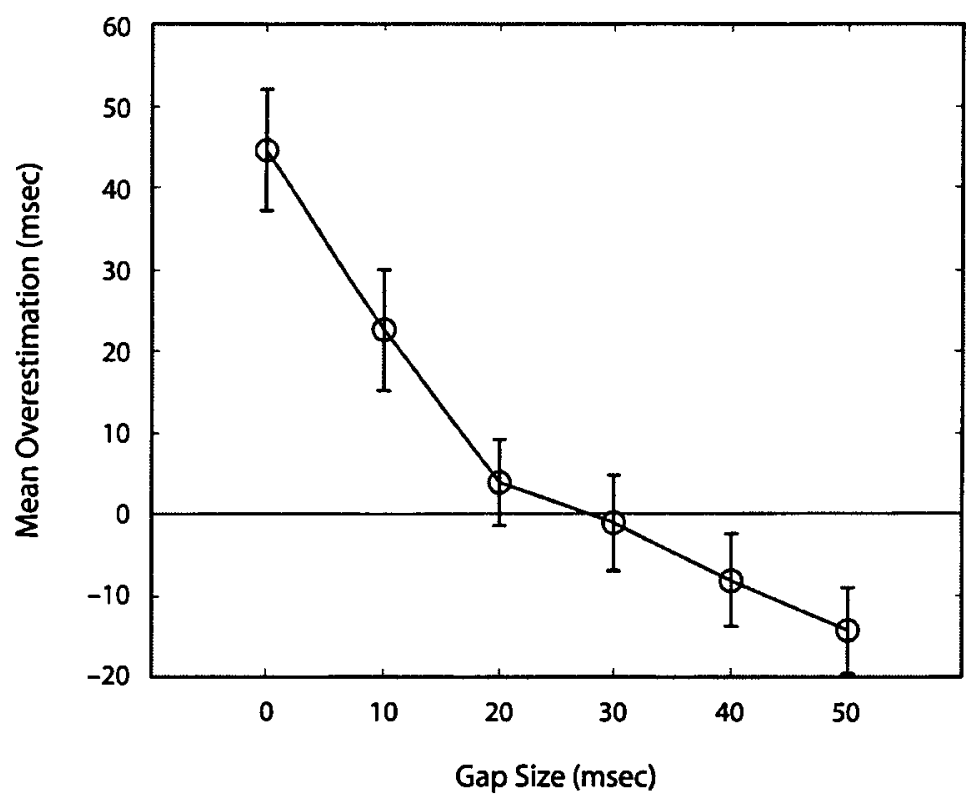

Figure 7. Experiment 4. Mean overestimations of the standard sine tone as a function of the size of the silent gap between the offset of the preceding band noise and the onset of the sine tone.

\section{EXPERIMENT 5}

The band noises used by Bakker et al. (1994) and Simons (1995) and those used in Experiments 1-4 of the present study were frozen. There is evidence in the literature that the masking characteristics of frozen noise can differ from that of nonfrozen (running) noise (e.g., Hartmann \& Pumplin, 1988; von Klitzing \& Kohlrausch, 1994). The purpose of the present experiment was to investigate whether we could replicate the time-stretching illusion when the sine tone was immediately preceded by nonfrozen band noise.

\section{Method}

Participants. Seven Kyushu University students with normal hearing and having experience with auditory experiments participated. Their age range was 22-25 years; 5 were male, and 2 were female.

Stimuli and Design. In the experimental conditions, $1000-\mathrm{H}_{2}$ $S_{\mathrm{ST}} \mathrm{s}$, having durations of $200,300,400$, and $500 \mathrm{msec}$, were immediately preceded by band noises of $1,500-\mathrm{msec}$ durations. In the control conditions, the sine tones were presented solely. The $C_{\mathrm{ST}} \mathrm{s}$ started $2,500 \mathrm{msec}$ after the offset of $S_{\mathrm{ST}}$. $S_{\mathrm{ST}}$ and $C_{\mathrm{ST}}$ had 10 -msec rise and fall times. The band noises had 400-msec rise times and 10 msec fall times. The ILDs between the band noise and sine tone were varied between $+10,0,-10$, and $-20 \mathrm{~dB}$. The bandwidth of the nonfrozen noises was one octave, centered logarithmically around $1000 \mathrm{~Hz}$; thus the edges were 707 and $1414 \mathrm{~Hz}$.

In the method of adjustment, there were ascending and descending trials-that is, the initial duration of $C_{\mathrm{ST}}$ was either clearly shorter or clearly longer than that of $S_{\mathrm{ST}}$. Table 3 shows the initial $C_{\mathrm{ST}}$ durations for each of the four $S_{\mathrm{ST}}$ durations. Because there were two replications, there were 4 (ILDs) $\times 4$ (tone durations) $\times$ 2 (ascending/descending) $\times 2$ (replications) $=64$ experimental trials, and 4 (tone durations) $\times 2$ (ascending/descending) $\times 2$ (replications) $=32$ control trials.

Procedure and Apparatus. Before the experiment proper, the participants received training with a small but representative number of adjustment trials. In a sound-attenuating booth, they individually lengthened (for ascending conditions) or shortened (for descending conditions) the duration of $C_{\mathrm{ST}}$ by pressing LENGTHEN and SHORTEN panes on the monitor. They were instructed to use as many successive presentations of $S_{\mathrm{ST}}$ as they needed and to change $C_{\mathrm{ST}}$ until they were satisfied with the equality of the durations of $S_{\mathrm{ST}}$ and $C_{\mathrm{ST}}$. When they were satisfied, they had to click the PLAY pane on the monitor upon which the last duration of $C_{\mathrm{ST}}$ was registered as the PSE of $S_{\mathrm{ST}}$ and the next trial started after $1,000 \mathrm{msec}$. The 96 trials (64 experimental and 32 controls) were randomized and divided equally over three sessions. The 32 trials in each session were preceded by 5 warm-up trials. Each session took about $75 \mathrm{~min}$, and there was a short break halfway.

The course of the experiment was steered by a program written in Microsoft Visual Basic 2005, running on an IBM-compatible computer (Frontier, FXNR-C24). The sound stimuli were generated with a $44.1-\mathrm{kHz}$ sampling rate and a quantization of 16 bits. The stimuli were presented binaurally through a D/A converter (Fostex, VC-8), a low-pass filter (NF, DV-04) with a 15-kHz cutoff frequency, and an equalizer (Roland, RDQ-2031) to an adaptor and headphones (Stax, SRM-313 and SR-303, respectively). Sound-pressure levels were measured with an artificial ear (Brüel \& Kjaer, 4153) and a sound-level meter (Nagano, 2075), and they were $68 \mathrm{~dB}(\mathrm{~A})$ for the sine tones and the band noise in the $0-\mathrm{dB}$ condition. In the other ILD conditions the band-noise levels were 78,58 , and $48 \mathrm{~dB}(\mathrm{~A})$

Table 3

Ranges (in Milliseconds) From Which the Initial Comparison Values in the Method of Adjustment Used in Experiment 5

Were Chosen for Ascending and Descending Trials When the Standard Sine-Tone Duration Was 200, 300, 400, or 500 msec

\begin{tabular}{crc}
\hline Sine-Tone Duration & Ascending & Descending \\
\hline 200 & $70-90$ & $340-360$ \\
300 & $135-165$ & $485-515$ \\
400 & $180-220$ & $630-670$ \\
500 & $225-275$ & $725-775$ \\
\hline
\end{tabular}




\section{Results and Discussion}

The mean overestimations at the 16 treatment combinations (four tone durations $\times$ four ILDs) are displayed in Figure 8. Visually comparing Figure 8 with Figure 3 (as regards equal tone durations of $200,300,400$, and $500 \mathrm{msec}$ in both figures) reveals that the pattern of overestimations in Experiments 1 and 5 is by and large the same: an increase of time stretching with increasing tone durations and a decrease with decreasing ILD between band noise and tone.

For all conditions and for each participant, we calculated the amount of overestimation by subtracting the appropriate control PSEs from the experimental PSEs. After that we averaged the overestimations over the ascending/ descending trials and over replications. We ran a 4 (tone duration) $\times 4$ (ILD) $\times 7$ (participants) repeated measures ANOVA. The main effect of tone duration was significant $\left[F(1.881,11.288)=7.15, p<.011, \eta_{\mathrm{p}}^{2}=.544\right]$. The main effect of ILD was significant as well $[F(2.437,14.620)=$ $\left.58.67, p<.0000001, \eta_{\mathrm{p}}^{2}=.907\right]$. The interaction effect was also significant $[F(2.881,17.286)=3.56, p<.037$, $\left.\eta_{\mathrm{p}}^{2}=.372\right]$.

Following the overall ANOVA, we ran three 4 (tone duration) $\times 2$ (ILD) $\times 7$ (participants) repeated measures ANOVAs, one for $+10 \mathrm{~dB}$ versus $0 \mathrm{~dB}$, one for $0 \mathrm{~dB}$ versus $-10 \mathrm{~dB}$, and one for $-10 \mathrm{~dB}$ versus $-20 \mathrm{~dB}$. The respective outcomes were $F(1,6)=7.98, p<.03 ; F(2.242$, $13.451)=32.91, p<.000001$; and $F(1,6)=5.87, p<$ .052 . It is clear that the decrease of time stretching was huge when going from 0 to $-10 \mathrm{~dB}$, but the decreases from +10 to $0 \mathrm{~dB}$ and from $-10 \mathrm{~dB}$ to $-20 \mathrm{~dB}$ were much smaller. Because we made three a posteriori comparisons, we chose a per family error rate of .05 and corrected that level by the Bonferroni procedure to $.05 / 3=.0167$. Thus, the latter two decreases of overestimation failed to reach significance. Nevertheless, there was a tendency toward diminishing amounts of time stretching with decreasing ILD between band noise and sine tone.

The important conclusion is that significant and robust time stretching can also be observed when applying nonfrozen band noises instead of frozen ones. Quantitatively, the amounts of overestimation in the present experiment at +10 and $0 \mathrm{~dB}$ ILD (on average 58 and $45 \mathrm{msec}$ ) were strikingly similar to the amounts at +6 and $0 \mathrm{~dB}$ in Experiment 1 at the comparable tone durations of 200,300, 400 , and $500 \mathrm{msec}$ (on average, 64 and $42 \mathrm{msec}$ ).

\section{GENERAL DISCUSSION}

\section{Summary of Results}

The results of Experiments 1 and 2 offered clear evidence that the degree of onset deterioration is affected by the intensity and frequency relationships between the band noise and the trailing sine tone. A more intense preceding band noise blurs the onset of the sine tone to a greater extent, and a band noise whose frequency range includes the frequency of the trailing sine tone blurs its onset to a big extent as well. Large overestimation of the tone duration can occur in such cases. If the noise is weak relative to the sine tone, or if the frequency range of the noise is far away from the sine tone, it should be easier for the listener to hear out the onset of the sine tone, thus little or no overestimation should take place. These aspects of onset blurring are similar to some aspects of simultaneous or forward auditory masking (e.g., Fastl \& Zwicker, 2006; Moore, 2003), which should not be surprising if the same peripheral auditory system is involved. Experiment 3 showed that time stretching also occurred when the preceding band noise had considerably shorter durations than the ones used in Experiments 1 and 2. Even band noises as short as 50 and 100 msec caused relatively large overestimations (about 45 and $65 \mathrm{msec}$, respec-

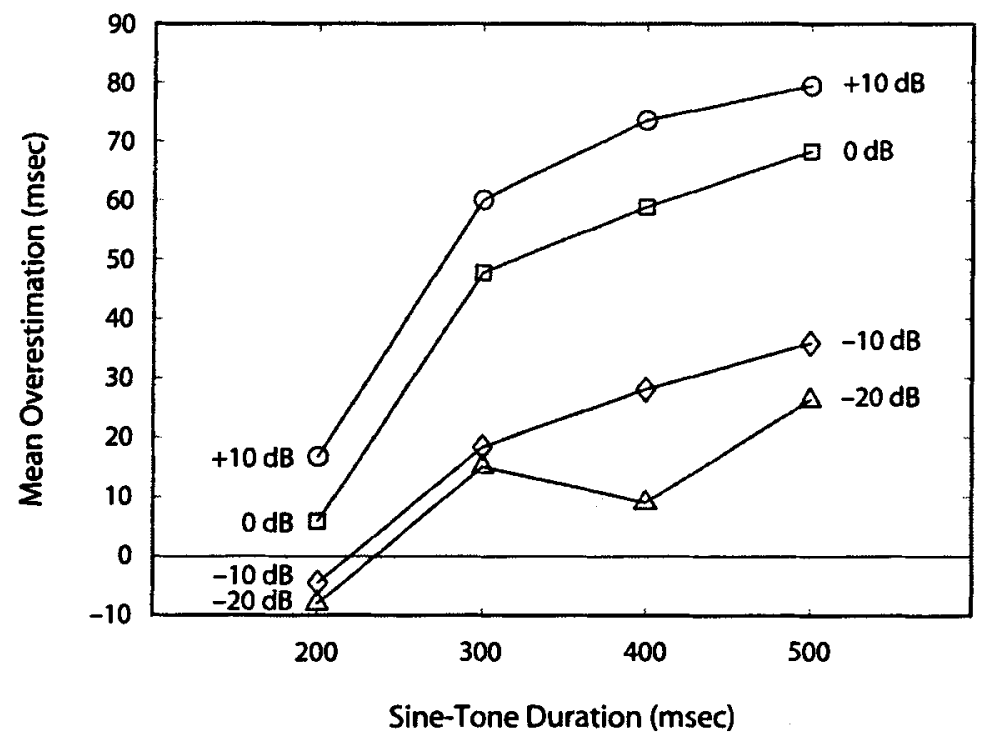

Figure 8. Experiment 5. Mean overestimations of the sine-tone duration as a function of tone duration and the ILD between the preceding nonfrozen band noise and the adjacent sine tone. 
tively). Experiment 4 demonstrated that insertion of a silent gap of $10 \mathrm{msec}$ between the band noise and the sine tone strongly diminished time stretching, and, when the gap was $20 \mathrm{msec}$, there was a release from time stretching. Experiment 5 showed that time stretching could also be observed clearly when the preceding band noises consisted of nonfrozen noise.

We initially surmised that the time-stretching illusion might be related to the continuity illusion (Sasaki et al., 1993). Although both illusions may have a few common aspects, they should not be considered as two variations of the same phenomenon. First, no stimulus pattern employed in the present study gives a strong cue that a tone might continue through a preceding noise because there is no tone preceding the noise. Second, the occurrence of time stretching does not necessarily require that the preceding noise be more intense than the trailing tone; even when the band noise was at the same level as the trailing tone or below, the overestimation of the tone is significant in many cases.

We posit that time stretching is caused by two perceptual stages. In the first, peripheral, stage, the onset of the sine tone is blurred. If the band noise can cause forward masking of the very first part of the sine tone, the latter's onset should be blurred. Even when the masking is incomplete or when the temporal boundary between the noise and the tone is just unclear, the blurring of the onset can take place, but we need more empirical data on this issue. In the second, central, stage, the blurred onset is perceptually restored, taking mental processing time that adds to the sine-tone duration. Restoration of the sound pattern enables the task of duration judgment and opens the possibility to perceptually reorganize the sound pattern.

\section{Event Construction Model and \\ Its Auditory Grammar}

The concept of auditory stream is fundamental in understanding auditory organization, and it is the core of Bregman's (1990) auditory scene analysis. Such a stream, for example a melodic phrase, is a concatenation in time of auditory events, in this case musical tones and silences. Nakajima (1996) and Nakajima and Sasaki (1996) presented a model for auditory organization at the level of auditory events and subevents. The key idea of the model is that the perceptual system parses auditory events (e.g., a musical tone) into auditory subevents (like tone onset, sustained tonal part, termination, and silence). The subevents, described formally shortly, are syntactic components that should conform to a logical grammar, in this case a simple Markov grammar (see Figure 9), developed by the above authors. The grammar describes the order in which the components (auditory subevents) can be glued together again. In linguistics, a grammar has only one input string of components at a time (to test the conformability of the logical components to the logical grammar). However, in our soundscape or in the perceptual laboratory, more auditory events (e.g., two) are often present at the same time, which means the grammar is confronted with two sets of syntactic elements. Thus, there should be (psycho)logical informa- tion for the grammatical process to order and glue the subevents. Such information, the model holds, is provided by auditory Gestalt principles (proximity, similarity, continuity), and can result in connecting subevents arising from different physical sounds. Consequently, the physical input strings and perceptual output strings are not isomorphic. We then speak of an auditory illusion. Nakajima and Sasaki showed (Nakajima, 1996; Nakajima \& Sasaki, 1996) that the model could satisfactorily describe several auditory illusions (e.g., continuity, gap-transfer, and split-off illusions). Nakajima et al. (2000) proposed the name event-construction model, and several follow-up studies refined this model (Kanafuka, Nakajima, Remijn, Sasaki, \& Tanaka, 2007; Kuroda, Nakajima, Tsunashima, \& Yasutake, 2009; Nakajima, 2006a, 2006b; Nakajima, Sasaki, Remijn, \& Ueda, 2004; Remijn \& Nakajima, 2005; Remijn, Nakajima, \& Tanaka, 2007; Remijn, Pérez, Nakajima, \& Ito, 2008).

Nakajima (2008) gave a detailed description of the model, which we quote here:

(1) Cues of auditory subevents, i.e., onsets, offsets (terminations), fillings, and silences, are detected by the auditory system as if they were independent events.

(2) A rapid increase of sound intensity within a certain frequency range can be a cue of an onset, and a rapid decrease of sound intensity

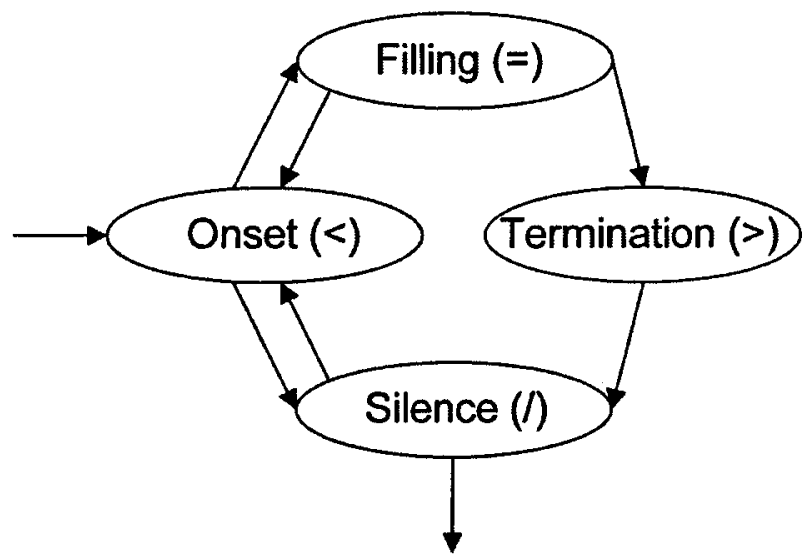

Figure 9. A Markov model generating grammatical auditory streams. The key idea of this grammar is that there are elements smaller than auditory events, so-called "subevents." The subevents are onset (corresponding to a steep rise of sound intensity, symbolized by <), filling (corresponding to a piece of sound energy extending for a certain duration, symbolized by $=$ ), offset or termination (corresponding to a steep fall of sound intensity, symbolized by $>$ ), and silence (corresponding to strongly attenuated sound energy, symbolized by $/$ ). Our auditory perceptual system provides cues as to which subevents, and in which order, constitute the event. There are rules determining which temporal orders of elements are grammatical and which ones are not. If it is difficult to interpret the cues of auditory subevents grammatically, the auditory system might insert new subevents, suppress some cues, or even reconnect subevents by applying Gestalt principles such as proximity, similarity, or continuity. This is done parsimoniously, such that the number of resulting auditory streams is small. 
within a certain frequency range can be a cue of an offset. A certain amount of sound energy within a time-frequency range can be a cue of a filling, and a lack of sound energy for some duration can be a cue of a silence.

(3) Detected cues are organized sequentially, as subevents, to form auditory streams, and any auditory stream should obey a simple grammar, in which a stream is either a single auditory event or a linear concatenation of auditory events. The last subevent of an auditory stream should be a silence.

(4) An auditory event is a linear concatenation of auditory subevents - that is, (a) an onset and a silence, (b) an onset and a filling, or (c) an onset, a filling, an offset, and a silence.

(5) The number of concurrent auditory streams is minimized.

(6) Reinterpretations, restorations, and suppressions of subevents are invoked, if necessary, to make auditory streams grammatical.

(7) The same cue is not interpreted twice unless the context calls for it more than once.

(8) Cues of onsets and offsets tend to be connected with each other perceptually, into a single stream or a single event, when they are close to each other in time and frequency (the proximity principle).

(9) Cues of fillings tend to be connected with each other perceptually, into a single stream or single event, when they indicate continuity or similarity in terms of spectra and intensity. (p. 301)

A description of the model and its auditory grammar from a phonetic/phonology point of view is given by Reiss (2007).

\section{Analyses of the Continuity and Time-Stretching Illusions}

The stimulus pattern giving rise to the continuity illusion (when part of a pure tone is replaced by more intense noise sharing the same frequency) can be written as the following string of subevents, or subevent cues, more exactly. The symbols for the subevents are $<$ (onset), = (filling), $>$ (termination), and / (silence). The order of the subevent cues is alphabetized for reference purposes:

$$
\begin{array}{llllllll}
\text { a } & \text { b } & \text { c } & \text { d } & \text { e } & \text { f } & \text { g } & \text { h } \\
< & = & < & = & > & = & > & /
\end{array}
$$

This stimulus pattern contains two cues of onset (of the tone and of the noise) and two cues of termination (of the noise and of the tone). However, this string is ungrammatical because the first termination (at $e$ ) is not followed by a silence. In addition, the onset cue of the tonal part $\mathrm{fg}(=>)$ is blurred by the noise cde $(<=>)$. Hence, the string does not yield an auditory stream. The auditory system is posed with a problem, which it solves as follows: The proximity principle connects the onset (at $c$ ) with the termination (at e) including the filling (at d), and a silence, although without a physical cue, is inserted after the termination (denoted IS for inserted silence). The resulting grammatical auditory stream is as follows:

$$
\begin{array}{lll}
\text { c } & \text { d } & \text { e IS } \\
< & = & >1
\end{array}
$$

The remainder of the subevents are

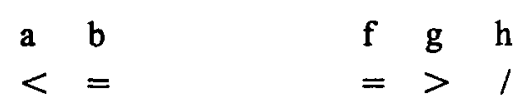

Because there are no cues of any subevents between the two fillings (at $b$ and $f$ ), and because there is no evidence that $b$ and $f$ belong to different events, there is no perceptual reason to keep the two fillings divided. Thus, a second grammatical stream arises:

$$
\begin{array}{llllllll}
\text { a } & \text { b } & \text { c } & \text { d } & \text { e IS } & \text { f } & \text { g } & \text { h } \\
& < & = & >/ & & & \\
< & & = & & & > &
\end{array}
$$

In sum, the auditory system solved the problem of ungrammaticality of the string of subevents by creating two streams (a continuous tone and a superimposed shorter noise).

We now explain the time-stretching illusion. Given that the onset of the tone to be judged for duration is masked by the preceding band noise, the string of subevent cues representing the pattern is as follows:

$$
\begin{array}{lllll}
\text { a } & \text { b c d } & \text { e } & \text { f } \\
< & = & > & > & /
\end{array}
$$

This string of subevents is not grammatical, because the filling of the sine tone (at d) is not preceded immediately by an onset. The onset cue of the tone de $(=>)$ is blurred by the preceding noise abc $(<=>)$. Still, the listener is required to judge the duration of the tone, and it is evident this cannot be done without an onset of the tone. The easiest solution for the auditory system is to restore an onset (denoted by RO for restored onset). As a consequence, the string of subevents becomes the following:

$$
\begin{array}{llllll}
\text { a } & \text { b } & \text { c RO } & \text { d } & \text { e } & \text { f } \\
< & = & > & = & > & \text { l }
\end{array}
$$

However, the auditory grammar (see Figure 9) does not allow that an onset (RO) immediately follows a termination (c). The grammatical solution is to insert a silence (denoted IS) between the termination (at $c$ ) and the onset (at RO). The string of subevents is now as follows:

$$
\begin{aligned}
& \text { a b c IS RO } d \text { e } f \\
& <=>1<=>1
\end{aligned}
$$

Although this string is formally grammatical, it does not seem to reflect the perceived temporal structure of the stimulus pattern very well. As we described in the introduction, listeners claim that the sine tone already appears to have started before the preceding band noise has 
Table 4

Linear Regression Equations of the Sine-Tone Overestimations From 200 to 500 msec in Experiments 1, 2, and 5 (cf. Figures 3, 4, and 8, Respectively) at Those Conditions That Yielded Maximum Overestimation (+6-dB Intensity-Level Difference [ILD] in Experiment 1;

0-Octave Difference at 500, 1000, and $2000 \mathrm{~Hz}$, Respectively, in Experiment 2; and +10-dB ILD in Experiment 5)

\begin{tabular}{llll}
\hline & Estimated Overestimation (msec) & $R^{2}$ & $p$ \\
\hline Experiment 1 & $-25.20+0.257$ (tone duration) & .97 & $<.015$ \\
Experiment 2 & $-14.70+0.159$ (tone duration) & .99 & $<.005$ \\
& $2.87+0.166$ (tone duration) & .90 & $<.051$ \\
& $0.02+0.195$ (tone duration) & .95 & $<.028$ \\
Experiment 5 & $-12.75+0.199$ (tone duration) & .85 & $<.078$ \\
\hline
\end{tabular}

finished (see note 2). Thus, rather than maintaining one string with two consecutive subevents without physical cues (IS and RO), the perceptual system seems to have divided the string of subevents into two auditory streams, allocating IS to the end of one stream and RO to the beginning of the other:

$$
\begin{array}{cccccc}
\text { a } & \text { b } & \text { RO c IS } & \text { d } & \text { e } & \text { f } \\
< & = & >1 & & & \\
& & < & = &
\end{array}
$$

The overlap of the two strings of subevents, each representing a separate stream, is of course typographical and does not suggest an exact time scale. At the end of the General Discussion, we propose an experimental paradigm to determine the amount of temporal overlap.

\section{Time Stretching and Sine-Tone Duration}

We amply discussed the extent of time stretching as a function of intensity and frequency relations between band noise and sine tone. As regards temporal/duration relations, we discussed only that stretching of the tone is nullified if a short silent gap (10-20 msec) is inserted between noise and tone (Experiment 4). Experiments 1, 2, and 5 showed significant effects of sine-tone duration on the amount of its overestimation. We try to explain this duration effect here. In the respective experiments the preceding band noises had a constant duration $(1,000,1,000$, and $1,500 \mathrm{msec}$, respectively), and the trailing adjacent sine tone varied from 200 to $800 \mathrm{msec}$ (Experiment 1), from 100 to $800 \mathrm{msec}$ (Experiment 2), and from 200 to $500 \mathrm{msec}$ (Experiment 5). Figures 3, 4, and 8 show that the amount of overestimation increased approximately linearly up to 500- and 600-msec tone durations. We fitted linear regression equations through the mean overestimations at $200,300,400$, and $500 \mathrm{msec}$ (the tone durations common to Experiments 1,2, and 5) for those conditions in which stretching was highest, and Table 4 shows that the $R^{2}$ values are quite satisfying. In keeping with the restoration-time notion, the linear increase of overestimation would mean that the time to restore the blurred 10msec onset waveform $(<)$ is in linear proportion to the duration of the sine tone. However, we cannot conceive of any underlying process, because whatever duration the sine tone has, only its blurred onset has to be restored; thus, it seems more reasonable to assume that restoration time is a constant (for a certain amount of blurring).

There are several constants of time perception: Studies by Nakajima and colleagues have shown that the time to mentally process the objective duration of an empty interval is $80 \mathrm{msec}$, which adds to it, yielding the subjective duration (Nakajima, 1987; Nakajima, Nishimura, \& Teranishi, 1988). Ten Hoopen and colleagues showed that sequences of empty time intervals presented interaurally are stretched such that each interval is $25 \mathrm{msec}$ longer than its monaural counterpart (Akerboom, ten Hoopen, Olierook, \& van der Schaaf, 1983; ten Hoopen, Vos, \& Dispa, 1982). An example of a longer constant is a 250msec time window, within which the difference limen (DL) for temporal discrimination is constant (on average $10 \mathrm{msec}$ ), but beyond which the Weber fraction is constant (on average 3\%) (see Friberg \& Sundberg, 1995; ten Hoopen, 1992; and ten Hoopen et al., 1994). For a taxonomic model of many more mental-timing constants, see Geisser and Kompass (2003). Following our conviction that onset restoration time is also a constant and adds to the sine-tone duration, we now consider whether classic phenomena like assimilation and/or contrast effects in time (see Fraisse, 1978, but note that he often used the term distinction for contrast) operate on the grammatically restored perceptual pattern. It should be emphasized that assimilation/contrast, of course, can work only after onset restoration is complete, because the duration clues should be clearly perceptible for these processes to work.

Let us try to explain whether these processes can cause the linear increase of overestimation with increasing tone durations. One caveat is in order: Although we are familiar with several assimilation and contrast studies employing empty time intervals, we know little about assimilation and contrast of adjacent filled durations, and we know even less about them when the two filled durations are heterophonic sounds (1/3-octave band noise-sine tone in the present study). However, let us suppose that these phenomena also hold for consecutive filled heterophonic sounds. As the constant of onset restoration time, we choose $100 \mathrm{msec}$, close to the maximum amounts of overestimation established in Experiment $1(102 \mathrm{msec}$ at the 500- and $106 \mathrm{msec}$ at the 600-msec tone duration) and not too far from the average maximum in Experiment 2 (about $90 \mathrm{msec}$ ). Hence, the restored pattern durations are 
$1,000-300,1,000-400,1,000-500$, and $1,000-600 \mathrm{msec}$. The contrast process might operate, at least on the first three patterns, in which the duration differences are relatively large. Contrast might boost these differences by perceptually compressing the sine tone and dilating the preceding band noise. In the time domain, contrast and assimilation effects might be asymmetric, but this is not relevant for our present purpose, because we are interested only in the compressing of the sine tone. We posit that contrast effects increase with increasing duration difference - that is, the 300-msec sine tone is compressed more than the $400-\mathrm{msec}$ sine tone, and so on. We further posit that the amount of compressing by contrast subtracts from the (restored) sine-tone duration. Now we can derive the amounts of compression as the complements of the overestimations. The linear regression equation in Table 4 (Experiment 1) estimates the overestimations of 200,300, 400 , and $500 \mathrm{msec}$ as $26,52,78$, and $103 \mathrm{msec}$, which we round here for instructive reasons to $25,50,75$, and $100 \mathrm{msec}$, and the (rounded) complements were $100-$ $25=75,100-50=50,100-75=25$, and $100-$ $100=0 \mathrm{msec}$. Thus, the restored sine-tone durations of $300,400,500$, and $600 \mathrm{msec}$ were compressed perceptually by the contrast process to $225,350,475$, and $600 \mathrm{msec}$, respectively. In conclusion, all sine-tone durations were lengthened by a 100 -msec onset-restoration time, but, by virtue of the subsequent contrast process, time stretching was reduced thereby when tones got shorter.

Consider now the $1,000-800 \mathrm{msec}$ pattern in Figure 3 at $+6 \mathrm{~dB}$. After sine-tone restoration, the duration pattern was 1,000-900 msec, and, because the durations of band noise and tone do not differ much, assimilation may have operated to regularize the duration pattern even more, yielding a perceptual outcome of, for example, 980$940 \mathrm{msec}$. Thus, whereas the above explanation in terms of contrast appeared to work, the explanation in terms of assimilation predicts an overestimation of $940-800=$ $140 \mathrm{msec}$, whereas we observed only about $70 \mathrm{msec}$. At present we cannot explain this discrepancy.

\section{Time Stretching and Band-Noise Duration}

In Experiment 3, the extent of sine-tone overestimation varied with band-noise duration. For the $300-\mathrm{msec}$ sine tone, its overestimations reached a plateau when the band noise had increased to $300 \mathrm{msec}$. For the 700 -msec sine tone, there was a further increase of its overestimation when the band noise got longer than $300 \mathrm{msec}$. In addition to the above explanation in terms of higher perceptual processes (grammatical onset restoration and contrast), Experiment 3 allows us to interpret the peripheral acoustic effect of blurring on the size of sine-tone overestimation.

We performed Experiment $3 \mathrm{~A}$ to establish the $\mathrm{dB}$ values of short band-noise durations that had equal loudness (see Figure 5) and Experiment 3B to investigate the effect of these short band noises on the amount of sine-tone overestimation. Figure 6 shows that, even though loudnesses were equal, sine-tone overestimation increased from about 45 to $100 \mathrm{msec}$ as the band-noise duration grew from 50 to $300 \mathrm{msec}$. The longer the band-noise duration, the more the sine-tone onset appeared to be blurred, and the fact that the pattern of overestimations did not differ (up to 300-msec band noise) between different durations of the trailing sine tones $(300$ and $700 \mathrm{msec})$ supports the notion that these sine-tone overestimations are pure restoration times, because subsequent contrast/assimilation effects would otherwise have yielded strikingly different overestimation patterns. Another piece of evidence for pure onset blurring and restoration thereof is that the increase of overestimation (averaged over 300- and 700-msec tones) up to 300-msec band-noise duration is perfectly logarithmic $\left(R^{2}=.987\right.$, $p<.001$ ), whereas overestimations in which restoration time and tone duration compression (by contrast) add together and display a linear increase of overestimation.

The overestimation at 300 -msec band-noise duration was $108 \mathrm{msec}$ for the $300-\mathrm{msec}$ tone and $114 \mathrm{msec}$ for the 700 -msec tone. These values did not differ, and the average value of $111 \mathrm{msec}$ is very close to the round value of $100 \mathrm{msec}$ of Experiment 1 (actually, the estimated value was $103 \mathrm{msec}$ ). Note that in Figure 6, band-noise durations of 400 and $500 \mathrm{msec}$ (beyond the critical duration of $300 \mathrm{msec}$ ) caused overestimations of the 300-msec sine tone that remained precisely at a $100-\mathrm{msec}$ plateau. This is still another estimate for the constant restoration time! Beyond 300-msec band-noise duration, there was a clear dissociation between the 300 - and 700 -msec sine-tone overestimations. Whereas the overestimations of the 300msec sine tone stayed at the level of restoration time, those of the 700-msec tone kept increasing beyond that level, indicating that subsequent effects enlarged the overestimations. For example, the noise-tone pattern $400-700 \mathrm{msec}$ might have been contrasted to $360-740 \mathrm{msec}$ (to regularize it toward 1:2), thus adding $40 \mathrm{msec}$ to the restoration time of $100 \mathrm{msec}$, yielding an overestimation of $100+$ $40=140 \mathrm{msec}$ (in fact, it was $145 \mathrm{msec}$ ).

\section{Assimilation or Contrast to Total Pattern Duration?}

The attempts above to explain the patterns of time stretching were in terms of onset restoration and subsequent contrast and assimilation between the two neighboring durations (noise and tone). It has been brought to our attention that there might have been an interaction between the sine tone to be judged for its duration and the total pattern duration (band noise + sine tone). However, we deliberately devised the stimulus patterns used in Experiment 5 to guard against clear duration relations. Recall that the preceding band noise was extra long, namely $1,500 \mathrm{msec}$ longer than the 1,000-msec band noises in Experiments 1 and 2. Moreover, the band-noise onset was extremely gradual, having a 400-msec ramp. These measures were taken intentionally to make the duration relations in the total sound pattern vague. Despite that, a clear pattern of overestimations of the sine tone was established, comparable to the patterns found in Experiments 1 and 2.

\section{Prospective Experiments}

Our description of the phenomenon that the sine tone appears to start already before the band noise stops might 
have unintentionally suggested that the full perceptual restoration time overlaps with the band noise. Because we did not perform temporal measurements of the phenomenon, we cannot answer this important question. But the question opens avenues for important follow-up experiments. One could envisage a reaction time (RT) experiment, applying Donder's A-reaction time task, in which simple RTs are gathered to the start and stop of the preceding band noise, to the start and stop of the sine tone, and to the start and stop of the total pattern. The control RTs are those to the start and stop of the band noise and the sine tone presented in isolation. Hopefully, such RT tasks measure the perceived durations that might converge with the sine-tone durations established in the present study and could inform us about the perceived band-noise duration and its overlap with the sine tone.

\section{AUTHOR NOTE}

The present research was supported by Grants-in-Aid for Scientific Research 14101001, 19103003, and 20330152 from the Japan Society for the Promotion of Science and by a Grant-in-Aid from the 21st-Century Center of Excellence Program "Design of artificial environments on the basis of human sensibility" at Kyushu University, supported by the Japanese government. We thank Gaston Hilkhuysen for meticulously checking the MATLAB programs. We thank Åke Hellström, Hans-Henning Schulze, and Simon Grondin for their helpful comments. Correspondence concerning this article can be directed to T. Sasaki, Miyagi Gakuin Women's University, 9-1-1 Sakuragaoka, Aoba-ku, 981-8557 Sendai, Japan (e-mail: sasaki@mgu.ac.jp).

\section{REFERENCES}

AKerboom, S., ten Hoopen, G., Olierook, P., \& VAN der SChaAF, T. (1983). Auditory spatial alternation transforms auditory time. Journal of Experimental Psychology: Human Perception \& Performance, 9, 882-897.

Bakker, B., Balabanova, D., van Bommel, M., Hovers, M., \& VlasBLOM, K. (1994). De invloed van de heterofonische continuiteitsillusie op waargenomen toonduur (The influence of the heterophonic continuity illusion on perceived tone duration). Unpublished research report for the Faculty of Social and Behavioral Sciences, Leiden University, The Netherlands.

Bennett, K. B., Parasuraman, R., Howard, J. H., JR., \& O'Toole, A. J. (1984). Auditory induction of discrete tones in signal detection tasks. Perception \& Psychophysics, 35, 570-578.

BREGMAN, A. S. (1990). Auditory scene analysis: The perceptual organization of sound. Cambridge, MA: MIT Press.

Bregman, A. S., \& DanNenbring, G. L. (1977). Auditory continuity and amplitude edges. Canadian Journal of Psychology, 31, 151-159. doi: $10.1037 / \mathrm{h} 0081658$

Ciocca, V., \& Bregman, A. S. (1987). Perceived continuity of gliding and steady-state tones through interrupting noise. Perception \& Psychophysics, 42, 476-484.

DEuTsCH, D. (1986). Auditory pattern recognition. In K. R. Boff, L. Kaufman, \& J. P. Thomas (Eds.), Handbook of perception and human performance: Vol. 2. Cognitive processes and performance (pp. 1-49). New York: Wiley.

DEUTSCH, D. (1999). Grouping mechanisms in music. In D. Deutsch (Ed.), The psychology of music (2nd ed., pp. 299-348). San Diego: Academic Press.

ElFNER, L. F., \& CASKey, W. E. (1965). Continuity effects with alternately sounded noise and tone signals as a function of manner of presentation. Journal of the Acoustical Society of America, 38, 543-547.

FASTL, H., \& ZWICKER, E. (2006). Psychoacoustics: Facts and models (3rd ed.). Berlin: Springer.

Fraisse, P. (1978). Time and rhythm perception. In E. C. Carterette \&
M. P. Friedman (Eds.), Handbook of perception: Vol. 8. Perceptual coding (pp. 203-254). New York: Academic Press.

FrIBERG, A., \& SundBerg, J. (1995). Time discrimination in a monotonic, isochronous sequence. Journal of the Acoustic Society of America, 98, 2524-2531. doi: 10.1121/1.413218

GeISSER, H.-G., \& KoMPASS, R. (2003). Invariants in mental timing: From taxonomic relations to task-related modeling. In H. Helfrich (Ed.), Time and mind II: Information processing perspectives (pp. 185-207). Göttingen: Hogrefe \& Huber.

HANDEL, S. (1989). Listening: An introduction to the perception of auditory events. Cambridge, MA: MIT Press.

HartmanN, W. M., \& Pumplin, J. (1988). Noise power fluctuations and the masking of sine signals. Journal of the Acoustical Society of America, 83, 2277-2289.

Houtgast, T. (1972). Psychophysical evidence for lateral inhibition in hearing. Journal of the Acoustical Society of America, 51, 18851894.

Kanafuka, K., Nakajima, Y., Remijn, G. B., Sasaki, T., \& TANAKA, S. (2007). Subjectively divided tone components in the gap transfer illusion. Perception \& Psychophysics, 69, 641-653.

KLUENDER, K. R., \& JeNISON, R. L. (1992). Effects of glide slope, noise intensity, and noise duration on the extrapolation of FM glides through noise. Perception \& Psychophysics, 51, 231-238.

Kuroda, T., Nakajima, Y., Tsunashima, S., \& Yasutake, T. (2009). Effects of spectra and sound pressure levels on the occurrence of the gap transfer illusion. Perception, 38, 411-428. doi:10.1068/p6032

MilleR, G. A., \& LiCKLIDER, J. C. R. (1950). The intelligibility of interrupted speech. Journal of the Acoustical Society of America, 22, 167-173.

Mitsudo, T., Nakajima, Y., Remin, G. B., Takeichi, H., Goto, Y., \& ToBImatsu, S. (2009). Electrophysiological evidence of auditory temporal perception related to the assimilation between two neighboring time intervals. NeuroQuantology, 7, 114-127.

MoORE, B. C. J. (2003). An introduction to the psychology of hearing (5th ed.) San Diego: Academic Press.

Nakajima, Y. (1987). A model of empty duration perception. Perception, 16, 485-520.

NAKajIMA, Y. (1996, August). A simple grammar for auditory organization: Streams, events, and subevents. Paper presented at the XXVI International Congress of Psychology, Montreal.

NAKaJIMA, Y. (2006a). Auditory grammar: The event construction model and spoken language [Abstract]. Journal of the Acoustical Society of America, 120, 3203-3204.

NAKajima, Y. (2006b). Demonstrations of the gap transfer illusion. Acoustical Science \& Technology, 27, 322-324.

NaKaJIMA, Y. (2008). Illusions related to auditory grammar: Ten demonstrations in musical contexts. In K. Miyazaki, Y. Hiraga, M. Adachi, Y. Nakajima, \& M. Tsuzaki (Eds.), Proceedings of the IOth International Conference on Music Perception and Cognition, (pp. 301-304). Sapporo, Japan.

Nakajima, Y., Nishimura, S., \& Teranishi, R. (1988). Ratio judgments of empty durations with numeric scales. Perception, 17, 93118.

Nakajima, Y., \& Sasaki, T. (1996, December). A simple grammar of auditory stream formation. Third Joint Meeting Acoustical Society of America and Acoustical Society of Japan. Honolulu, Hawaii.

Nakajima, Y., Sasaki, T., Kanafuka, K., Miyamoto, A., RemiJn, G., \& TEN HOOPEN, G. (2000). Illusory recouplings of onsets and terminations of glide tone components. Perception \& Psychophysics, 62, 1413-1425.

Nakajima, Y., Sasaki, T., Reminn, G. B., \& Ueda, K. (2004). Perceptual organization of onsets and offsets of sounds. Journal of Physiological Anthropology \& Applied Human Science, 23, 345-349.

Nakajima, Y., TEN Hoopen, G., HilkhUYSen, G., \& Sasaki, T. (1992). Time shrinking: A discontinuity in the perception of auditory temporal patterns. Perception \& Psychophysics, 51, 504-507. doi:10.1068/p170093

Nakajima, Y., Ten Hoopen, G., Sasaki, T., Yamamoto, K., KaDota, M., Simons, M., \& Suetomi, D. (2004). Time-shrinking: The process of unilateral temporal assimilation. Perception, 33, 10611079. doi:10.1068/p5061 
NAKajima, Y., TEN Hoopen, G., \& VAN DER Wilk, R. G. H. (1991). A new illusion of time perception. Music Perception, 8, 431-448.

Plomp, R. (1981). Perception of sound signals at low signal-to-noise ratios. In D. J. Getty \& J. H. Howard, Jr. (Eds.), Auditory and visual pattern recognition (pp. 27-35). Hillsdale, NJ: Erlbaum.

PLOMP, R. (2002). The intelligent ear: On the nature of sound perception. Mahwah, NJ: Erlbaum.

REISS, C. (2007). Modularity in the sound domain: Implications for the purview of universal grammar. In G. Ramchand \& C. Reiss (Eds.), The Oxford handbook of linguistic interfaces (pp. 53-80). Oxford: Oxford University Press.

REMIJN, G. B., \& NAKAJIMA, Y. (2005). The perceptual integration of auditory stimulus edges: An illusory short tone in stimulus patterns consisting of two partly overlapping glides. Journal of Experimental Psychology: Human Perception \& Performance, 31, 183-192. doi:10.1037/0096-1523.31.1.183

Remijn, G. B., Nakajima, Y., \& Tanaka, S. (2007). Perceptual completion of a sound with a short silent gap. Perception, 36, 898-917.

Remuj, G. B., Pérez, E., Nakajima, Y., \& Ito, H. (2008). Frequency modulation facilitates (modal) auditory restoration of a gap. Hearing Research, 243, 113-120.

Remijn, G. B., van der Meulen, G., ten Hoopen, G., Nakajima, Y., KOMORI, Y., \& SASAKI, T. (1999). On the robustness of time-shrinking. Journal of the Acoustical Society of Japan (E), 20, 365-373.

RIECKE, L., van OPSTAL, A. J., \& Formisano, E. (2008). The auditory continuity illusion: A parametric investigation and filter model. Perception \& Psychophysics, 70, 1-12. doi:10.3758/PP.70.1.1

Sasaki, T., Nakaima, Y., \& TEN Hoopen, G. (1993). The effect of a preceding neighboring tone on the perception of filled durations [In Japanese, with English figure captions]. Proceedings of the Acoustical Society of Japan, spring meeting (pp. 347-348). Tokyo: Acoustical Society of Japan.

Sasaki, T., Suetomi, D., Nakajima, Y., \& ten Hoopen, G. (2002). Time-shrinking, its propagation, and Gestalt principles. Perception \& Psychophysics, 64, 919-931.

SCHARF, B., \& HoutSMA, A. J. M. (1986). Audition II: Loudness, pitch, localization, aural distortion and pathology. In K. R. Boff, L. Kaufman, \& J. P. Thomas (Eds.), Handbook of perception and human performance: Vol. I. Sensory processes and perception (pp. 15.1-15.60). New York: Wiley.

Simons, M. (1995). Time swelling: An incomplete heterophonic induction in a nonrepetitive design. Unpublished master's thesis, Leiden University, The Netherlands.

SUETOMI, D., \& NAKAJIMA, Y. (1998). How stable is time-shrinking? Journal of Music Perception \& Cognition, 4, 19-25.

Takeichi, H., Mitsudo, T., Nakajima, Y., RemiJn, G. B., Goto, Y., $\&$ ToBimarsu, $S$. (in press). A neural decoding approach to auditory temporal assimilation. Neural Computing \& Applications.

TEN HOOPEN, G. (1992, February). Temporal processing of fast auditory patterns. Paper presented at the 2nd International Conference on Music Perception and Cognition, Los Angeles.

TEn Hoopen, G., BoelaArTs, L., Gruisen, A. Apon, I., Donders, K., MuL, N., \& AKerboom, S. (1994). The detection of anisochrony in monaural and interaural sound sequences. Perception \& Psychophysics, 56, 110-120.

ten Hoopen, G., Hartsuiker, R., Sasaki, T., Nakajima, Y., TaNAKA, M., \& TsumURA, T. (1995). Auditory isochrony: Time shrinking and temporal patterns. Perception, 24, 577-593.
TEn Hoopen, G., Hilkhuysen, G., Vis, G., Nakaima, Y., Yamauchi, F., \& SASAKI, T. (1993). A new illusion of time perception: II. Music Perception, 11, 15-38.

ten Hoopen, G., Miyauchi, R., \& Nakajima, Y. (2008). Time-based illusions in the auditory mode. In S. Grondin (Ed.), Psychology of time (pp. 139-188). Bingley, U.K.: Emerald Group.

TEN HOOPEN, G., Vos, J., \& DisPA, J. (1982). Interaural and monaural clicks and clocks: Tempo difference versus attention switching. Journal of Experimental Psychology: Human Perception \& Performance, $8,422-434$.

THURLOW, W. R. (1957). An auditory figure-ground effect. American Journal of Psychology, 70, 653-654. doi:10.2307/1419466

UEDA, K., \& OHTSUKI, M. (1996). The effect of sound pressure level difference on filled duration extension. Journal of the Acoustical Society of Japan (E), 17, 159-161.

VAN NOORDEN, L. P. A. S. (1975). Temporal coherence in the perception of tone sequences. Unpublished doctoral dissertation, Eindhoven University of Technology, Eindhoven, The Netherlands.

VICARIO, G. (1960). L'effetto tunnel acustico. Rivista di Psicologia, 54, $41-52$.

VON KiItZING, R., \& KoHLRAUSCH, A. (1994). Effect of masker level on overshoot in running- and frozen-noise maskers. Journal of the Acoustical Society of America, 95, 2192-2201. doi:10.1121/1.408679

WARREN, R. M. (1982). Auditory perception: A new synthesis. New York: Pergamon.

WARREN, R. M. (1999). Auditory perception: A new analysis and synthesis. Cambridge: Cambridge University Press.

WARREN, R. M. (2008). Auditory perception: An analysis and synthesis. Cambridge: Cambridge University Press.

WARREN, R. M., BAShFord, J. A., Jr., Healy, E. W., \& Brubaker, B. S. (1994). Auditory induction: Reciprocal changes in alternating sounds. Perception \& Psychophysics, 55, 313-322.

WARREN, R. M., OBUSEK, C. J., \& ACKROFF, J. M. (1972). Auditory induction: Perceptual synthesis of absent sounds. Science, 176, 1149 1151.

WRIGHTSON, J. M., \& WARREN, R. M. (1981). Incomplete auditory induction of tones alternated with noise: Effects occurring below the pulsation threshold [Abstract]. Journal of the Acoustical Society of America, 69, S105-S106.

\section{NOTES}

1. In previous publications (i.e., ten Hoopen, Miyauchi, \& Nakajima, 2008 , but also in conference papers), we called this illusion "time swelling." We thank Hans-Henning Schulze for bringing to our attention that that term is inadequate, because swelling means an increase in three dimensions (like that of a pufferfish or globefish, family Tetraodontidae). He proposed "time stretching" as a more appropriate term for the illusory one-dimensional lengthening of the sine tone, and here we adopted that term gratefully.

2. The phenomenon that the sine tone appears to start before the band noise has finished can be heard in Demo 18, "A Backward Extension of a Tone," at our Web site: www.design.kyushu-u.ac.jp/ ynhome/ENG/ Demo/illusions2nd.html.

(Manuscript received September 4, 2009; revision accepted for publication March 13, 2010.) 